\title{
Biodiesel Supply Chain Network Design Under Hybrid Uncertainties: A Novel Multi-objective Robust Fuzzy Stochastic Approach
}

Mohsen Rezaei ( $\nabla$ mohsen.rezaei.10@gmail.com )

University of science and technology of Mazandaran https://orcid.org/0000-0001-9481-0212

\section{Research Article}

Keywords: Bioenergy, Biodiesel, Sustainable development, Supply chain network design, Hybrid uncertainties, Multi-objective robust fuzzy stochastic programming

Posted Date: August 10th, 2021

DOl: https://doi.org/10.21203/rs.3.rs-777381/v1

License: (c) (1) This work is licensed under a Creative Commons Attribution 4.0 International License.

Read Full License 


\title{
Biodiesel supply chain network design under hybrid uncertainties: a novel multi-objective robust fuzzy stochastic approach
}

\author{
Mohsen Rezaei ${ }^{\text {a, } 1}$ \\ ${ }^{a}$ Department of Industrial Engineering, University of Science and Technology of \\ Mazandaran, Behshahr, Iran
}

\begin{abstract}
In the biofuel supply chain, there may be various and hybrid uncertainties that, if ignored, can lead to inefficient network design. In this study, a multi-objective robust fuzzy stochastic programming (MORFSP) model is proposed for designing biodiesel supply chain network (BSCN) under different and hybrid uncertainties. This model simultaneously minimizes total cost of the BSCN and total environmental impacts of activities of the network. Fixed costs and environmental impact of opening facilities are described as fuzzy variables. Demands, supplies, other costs and environmental impacts are considered as fuzzy scenario based variables. The proposed MORFSP model considers different risks, including possibilistic variability and scenario variability related to economic and environmental objective functions, and unsatisfied demand costs. This model is applied in a real case study to design a BSCN in Iran. Waste cooking oil (WCO), and some non-edible plants like Salvia lerifolia (SL) and Jatropha Curcas L. (JCL) are considered as sources of producing biodiesel. The proposed approach used for designing a four-echelon, multi-period, and multi-product, of BSCN. The results show the effectiveness of the proposed model for designing the BSCN under hybrid uncertainties.
\end{abstract}

Keywords: Bioenergy; Biodiesel; Sustainable development; Supply chain network design; Hybrid uncertainties; Multi-objective robust fuzzy stochastic programming

\section{1-Introduction}

1 Corresponding author. Tel.: +98 11 34556011. P.O. Box 48518-78195

E-mail address: mohsen.rezaei.10@gmail.com (M. Rezaei). 
Sustainable development (SD) comprises a thorough and integrated way to the economic, social and environmentally functions (Karakosta and Askounis 2010). An SD approach seeks to provide services which meet basic human needs, in a cleaner and more efficient way that can be sustained in the future (Winkler 2007; Suganthi 2018). Nowadays, energy is undoubtedly crucial for sustainable development and the prosperity of a community (Chaharsooghi and Rezaei 2016; Tan et al. 2018). Increase of energy consumption causes some problems like depleting energy sources and creating pollution (Shakouri and Kazemi 2017). Increment in the energy efficiency of processes applying sustainable resources can very help in achieving sustainable development (Hepbasli 2010; Ulonska et al. 2018). There is a need to developing new energy resources to replace or reduce the use of nonrenewable energy resources (like natural gas, petroleum, coal, etc.) (Li et al. 2009; Ruiz et al. 2016; Rezaei et al. 2020a).

Renewable energies (REs) are considered as one of the potential solutions for climate change, energy security and sustainable growth (Huang et al. 2011; Swain and Karimu 2020). REs are produced applying harmless techniques that have less harmful impact on the environment in contrast to other kinds of energy (Chaharsooghi et al. 2015). So, renewable energy sources seem to be an effective solution for achieving sustainable development (Rezaei et al. 2013). Nowadays, developing RE is becoming a hot topic since it is crucial in dealing with energy supply issue and climate change issue (Cai et al. 2012; Salamanca et al. 2012).

Biomass is becoming among the most typically applied RE sources in the recent years. Biofuels are fuels produced from biomass sources that are commonly used for transportation (Mousavi Ahranjani et al. 2018). Bioethanol and biodiesel that include the most utilized liquid biofuels, are fine substitution for petrol and diesel, respectively (Babazadeh et al. 2017b). Biofuels can be used in existing engines with major modifications (Devarajan et al. 2017; $\mathrm{Xu}$ and $\mathrm{Xu} 2018$ ).

While the biomass is fairly cheap, the logistic costs play main role in the price of the biomass delivered to the biorefinery (Steiner et al. 2012; Atashbar et al. 2016). Since numerous producers of biomass are involved in this supply chain, quantitative models can be beneficial to assess and optimize the related costs, the required resources, and the consumptions of energy ( $\mathrm{Ba}$ et al. 2016).

Because of restriction of fossil fuel sources and their negative influences on environment, in recent years, there have been a lot of researches on designing biofuel supply chain. In designing the BSCN, the strategic decisions for instance the size, number, capacity and location of facilities, and the tactical decisions, like production quantity, mode of transportation, inventory, and transported product among various facilities are determined (An et al. 2011; Santibañez-Aguilar et al. 2016a).

In this article, multi-objective robust fuzzy stochastic programming model is presented for designing a BSCN under hybrid uncertainties. The main novelties of this study are summarized as follows:

- In this study, the different and hybrid uncertainties that exist in the real world in the biofuel supply chains are considered. So that some uncertain variables have fuzzy nature and some have fuzzy stochastic nature. 
- According to the literature, fuzzy stochastic approach has not been used to model the biofuel supply chain. Due to the specific characteristics of the supply chain of these fuels and excising different and hybrid uncertainties related to this field, in this study, a robust fuzzy stochastic programming model is proposed for designing the supply chain.

- A multi-objective robust fuzzy stochastic programming model is presented for designing a BSCN under different and hybrid uncertainties that simultaneously minimizes the total cost of the BSCN and the total environmental impacts of the activities of the supply chain.

- This model considers the different risks in the network, such as possibilistic variability and scenario variability related to economic and environmental objective functions, and unsatisfied demand costs.

- Possibility of capacity expansion of facilities in different periods is considered.

- The presented model is applied in a real case study in Iran.

The Structure of this article is as follows:

In Section 2, the researches related to this work are described. In Section 3, the mathematical formulation which groups the main constraints and the objective functions is discussed. In Section 4, the proposed robust fuzzy stochastic programming approach is presented. A case study to examine the proposed approach is discussed in Section 5. Lastly, the final conclusions are stated in Section 6.

\section{2- Literature review}

There are different methodologies for designing biofuels supply chain in the literature, like mathematical programming models, simulation, and GIS (Bai et al. 2011). The mathematical programming models were the most applied method (Ghaderi et al. 2016).

In this section, researches most related to our work are reviewed.

In the most studies, deterministic mathematical programming models were applied to design the BSCN.

Cambero et al (2015) developed a mixed integer linear programming (MILP) model to design a supply chain of forest residues. This model maximized the net present value of the supply chain over the horizon time. Ahn et al. (2015) presented a deterministic mathematical programming method for designing a BSCN which simultaneously considered resource, and demand constraints. This model helped for determining the location and the amount of feedstock, and the location and the size of refineries. Babazadeh et al. (2017c) proposed a method according to DEA approach and mathematical programming model for designing of BSCN. Firstly, locations for cultivating JCL were evaluated through unified DEA method based on some social and climatic criteria. Afterwards, the areas that had attained the desired scores were selected as candidate areas for cultivating JCL and by aILP model the BSCN model is designed. 
One of the challenges in designing the BSCN is existence of different uncertainties, including, biomass demand, supply, price, etc. (Bairamzadeh et al. 2018a). There are various approaches in the literature to dealing with uncertainty:

Some studies have used stochastic planning approach. For example, Giarola et al. (2011) proposed a two-stage stochastic mixed integer programming model to design a biofuel supply chain in the southeastern United States, in which biofuel supply, demand, price and technology are varied in different scenarios. Marufuzzaman et al. (2014) developed a stochastic programming method to design a BSCN under technology development and biomass supply uncertainties. They developed a MOMILP model that optimized costs and emissions of the network.

Fuzzy programming is another widely used approach in dealing with uncertainties. Tong et al. (2014a) presented a linear integer programming model to design a biofuel supply chain. To deal with the uncertainty of the parameters, they have used the fuzzy programming approach. To address the uncertainties, Babazadeh et al. (2017a) proposed a multi-objective possibilistic planning model for the second generation BSCN under uncertainty.

In recent years, the robust optimization approach has paid more attention due to its high capability in the face of risk and uncertainty (Bertsimas et al. 2011; Pishvaee and Khalaf 2016). Kim et al. (2011) developed a scenario-based robust MILP model for designing a biofuel supply chain network under demand uncertainty. Zhang and Jiang (2017) designed a BSCN model, which includes both strategic and tactical levels. They presented a multiobjective robust model under biodiesel price uncertainty. They took Suzhou, a city in China, as a case study for verifying the presented method.

Some of the studies that have used mathematical programming approach under uncertainty are summarized in Table 1 .

Table 1. A review of some biofuels supply chain network design studies under uncertainty

\begin{tabular}{|c|c|c|c|c|c|c|c|c|}
\hline \multirow{2}{*}{ References } & \multicolumn{2}{|c|}{ Modeling approach } & \multicolumn{2}{c|}{ Objective function } & \multicolumn{2}{c|}{ Uncertainty modeling approach } \\
\cline { 2 - 8 } & MOMILP & MILP & MINLP & Economical & Environmental & $\begin{array}{c}\text { Stochastic } \\
\text { programing }\end{array}$ & $\begin{array}{c}\text { Fuzzy } \\
\text { programming }\end{array}$ & $\begin{array}{c}\text { Robust } \\
\text { optimization }\end{array}$ \\
\hline $\begin{array}{c}\text { (Kim et al. } \\
\text { 2011) }\end{array}$ & & $*$ & $*$ & & $*$ & & \\
\hline $\begin{array}{c}\text { (Dal-Mas et } \\
\text { al. 2011) }\end{array}$ & & $*$ & $*$ & $*$ & & $*$ & & \\
\hline $\begin{array}{c}\text { (Awudu } \\
\text { and Zhang } \\
\text { 2012) }\end{array}$ & & $*$ & $*$ & & $*$ & & \\
\hline $\begin{array}{c}\text { (Tong et al. } \\
\text { 2014a) }\end{array}$ & & $*$ & $*$ & & & & \\
\hline $\begin{array}{c}\text { (Tong et al. } \\
\text { 2014b) }\end{array}$ & & & $*$ & & & & \\
\hline
\end{tabular}




\begin{tabular}{|c|l|l|l|l|l|l|l|l|}
\hline $\begin{array}{c}\text { (Santibañez } \\
\text {-Aguilar et al. } \\
\text { 2016b) }\end{array}$ & $*$ & & $*$ & $*$ & $*$ & & \\
\hline $\begin{array}{c}\text { (Quddus et } \\
\text { al. 2017) }\end{array}$ & & $*$ & $*$ & $*$ & $*$ & $*$ & \\
\hline $\begin{array}{c}\text { (Babazadeh } \\
\text { et al. 2017a) }\end{array}$ & & $*$ & $*$ & $*$ & & $*$ \\
\hline $\begin{array}{c}\text { (Bairamzad } \\
\text { eh et al. } \\
\text { 2018b) }\end{array}$ & & $*$ & & & & & \\
\hline
\end{tabular}

According to the literature, in the research related to biofuel supply chain modeling, different and hybrid uncertainties in the real world have not been considered. Therefore, in this study, a novel robust fuzzy stochastic programming model has been presented for this field. In this approach, some variables have fuzzy nature and some have fuzzy scenario nature. This model takes into account the different risks, including possibilistic variability, scenario variability, and unsatisfied demand costs. In addition, a multi-objective robust fuzzy stochastic programming model is presented for designing the BSCN under hybrid uncertainties that simultaneously minimizes the total cost of the network and the total environmental impacts of the activities.

\section{3- Problem description and formulation}

The structure of the presented BSCN is shown in Figure 1. It is a four-echelon, multiperiod, and multi-product supply chain network under hybrid uncertainties. As this figure shows, JCL and SL products are shiped from their corresponding cultivation centers to oil extracting facilities. JCL oil and SL oil are obtained in oil extraction facilities and transported to biorefineries. WCOs are collected from suppliers and transported to refineries for pretreating. In biorefineries, biodiesel is produced through JCL oils, SL oils, and waste cooking oils. Afterwards, the produced biodiesel is shipped from refineries to distribution facilities. Lastly, the biodiesel is shipped from distribution facilities to consumption centers. 


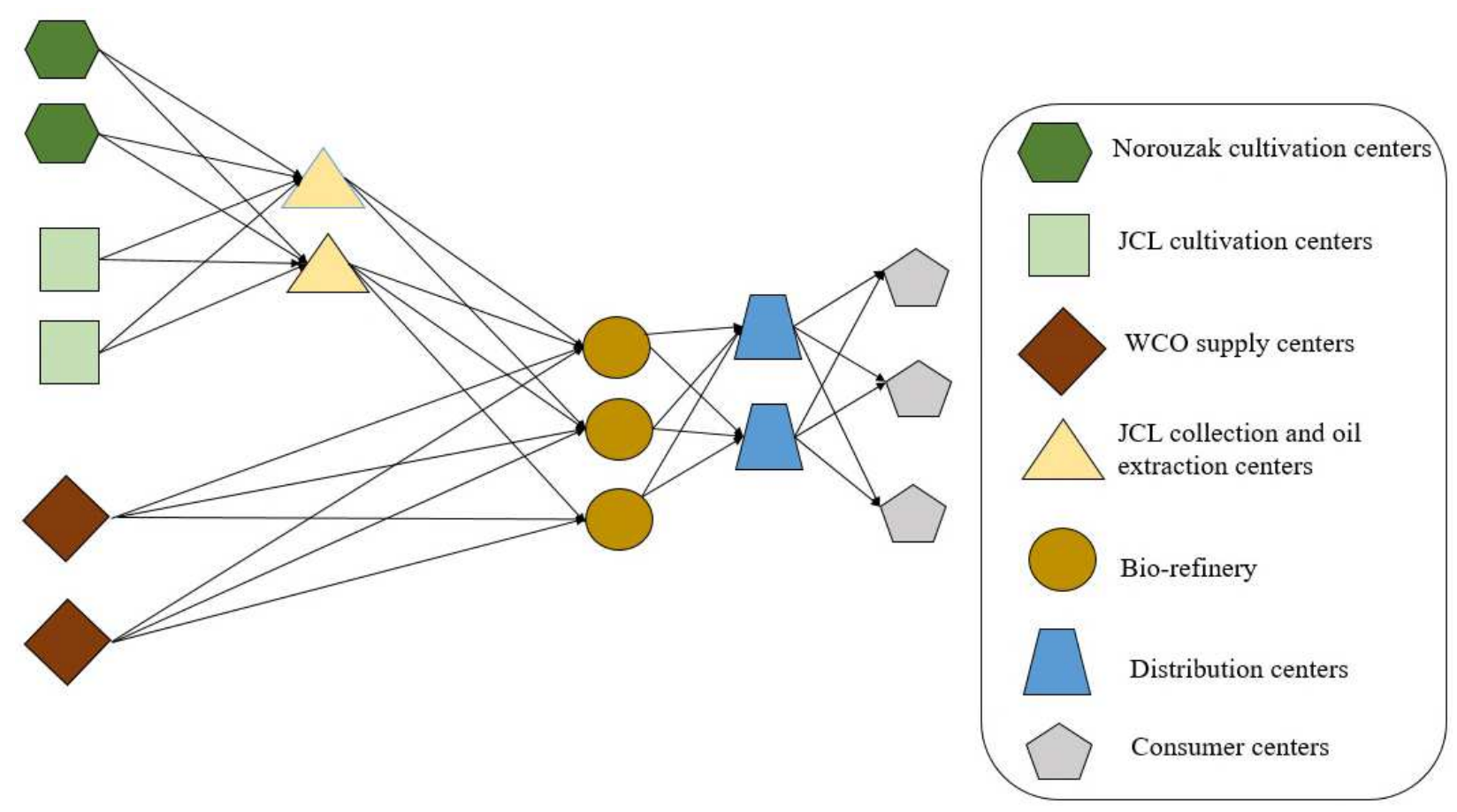

Figure 1. Proposed biodiesel supply chain network

\section{3-1- Assumptions and notations}

The general assumptions used for mathematical modeling are summarized as follows:

- The locations of biodiesel consumption centers are known and fixed.

- Potential areas for cultivating of JCL and SL and opening of other facilities are known.

- Transportation is done by 2 modes of road and rail.

- The capacity of JCL and SL farms, established oil extraction facilities, and distribution facilities are not fixed. These capacities are calculated over planning horizon by continuous variables.

- Required capacity for each refinery is calculated through adding capacity alternatives to the initial corresponding capacity.

- The opened facilities will be active until the end of the planning horizon.

- Fixed costs and environmental impact of opening facilities are uncertain and are described as fuzzy variables.

- Demands, supply of waste oils, the other costs, and some environmental impacts are uncertain and are considered as fuzzy scenario based variables.

The notations used to formulate the model are described in the following. It should be noted that uncertain parameters are introduced with a tilde on.

\section{Sets}

$f \quad$ Set of candidate locations for planting JCL 
Set of candidate locations for planting SL

Set of locations for waste oil supply sites

Set of candidate locations for oil extraction sites

Set of candidate locations for biorefinery sites

Set of candidate locations for biodiesel distribution sites

Set of biodiesel demand centers

Set of transportation modes

Set of capacity selection for refinery sites

Set of time period

Set of scenarios

\section{Technical parameters}

$\widetilde{D}_{m t s} \quad$ Biodiesel demand of consumer center $\mathrm{m}$ at year $\mathrm{t}$ in scenario s

$\widetilde{W O}_{g t s} \quad$ Amount of WCO supplied through supplier $\mathrm{g}$ at year $\mathrm{t}$ in scenario s

$L A_{f} \quad$ Minimum allowable area for cultivating JCL in area $\mathrm{f}$

$U A_{f} \quad$ Maximum allowable area for cultivating JCL in area $\mathrm{f}$

$L N_{n} \quad$ Minimum allowable area for cultivating SL in area $\mathrm{n}$

$U N_{n} \quad$ Maximum allowable area for cultivating SL in area $\mathrm{n}$

$L C_{i} \quad$ Minimum allowable capacity of oil extraction facility in area $\mathrm{i}$

$U C_{i} \quad$ Maximum allowable capacity of oil extraction facility in area $\mathrm{i}$

$L B_{j} \quad$ Minimum allowable biorefinery capacity in area $\mathrm{j}$

$U B_{j} \quad$ Maximum allowable biorefinery capacity in area $\mathrm{j}$

$L S_{k} \quad$ Minimum allowable capacity of distribution facility in area $\mathrm{k}$

$U S_{k} \quad$ Maximum allowable capacity of distribution facility in area $\mathrm{k}$

$\operatorname{Min} x \quad$ Minimum number of JCL cultivation centers

Min $y \quad$ Minimum number of SL cultivation centers

csl Percentage of customer service level

$\alpha \quad \alpha-$ cut

$\eta_{f t} \quad$ Amount of JCL products per hectare in area $\mathrm{f}$ at year $\mathrm{t}$

$\tau \quad$ Amount of SL products per hectare

$\theta \quad$ JCL conversion rate to its oil

$\varphi \quad$ SL conversion rate to its oil

$\beta \quad$ WCO conversion rate to its pre-treated form 


$\begin{array}{cl}\gamma & \text { JCL oil conversion rate to biodiesel } \\ \Delta & \text { SL oil conversion rate to biodiesel } \\ \omega & \text { Pre-treated WCO conversion rate to biodiesel } \\ C W_{j t} & \text { Initial biorefinery } \mathrm{j} \text { capacity at year } \mathrm{t} \\ R_{p j t} & \text { Capacity option } \mathrm{p} \text { for biorefinery } \mathrm{j} \text { at year } \mathrm{t} \\ p_{s} & \text { Probability of occurring scenario } \mathrm{s} \\ D J T_{f l i} & \text { Distance between JCL planting site } \mathrm{f} \text { and oil extracting facility i via mode } 1 \\ D N T_{n l i} & \text { Distance between SL planting site } \mathrm{n} \text { and oil extracting facility i via mode } 1 \\ D W T_{g l j} & \text { Distance between supplier } \mathrm{g} \text { and biorefinery } \mathrm{j} \text { via mode } 1 \\ D O T_{i l j} & \text { Distance between oil extracting facility } \mathrm{i} \text { and biorefinery } \mathrm{j} \text { via mode } 1 \\ D B T_{j l k} & \text { Distance between biorefinery } \mathrm{j} \text { and distribution facility } \mathrm{k} \text { via mode } 1 \\ D M T_{k l m} & \text { Distance between distribution facility } \mathrm{k} \text { and customer } \mathrm{m} \text { via mode } 1\end{array}$

\section{Cost parameters}

$\tilde{\pi}_{m t s} \quad$ penalty cost per unit of unsatisfied demand of consumer $\mathrm{m}$ at year $\mathrm{t}$ in scenario $\mathrm{s}$

$\widetilde{F C} J_{f} \quad$ Fixed cost for cultivating JCL in area $\mathrm{f}$

$\widetilde{F C N}_{n} \quad$ Fixed cost for cultivation of SL in area $\mathrm{n}$

$\widetilde{F C} C_{i} \quad$ Fixed cost for establishing oil extraction facility in area $\mathrm{i}$

$\widetilde{F C B}_{j} \quad$ Fixed cost for establishing biorefinery in area $\mathrm{j}$

$\widetilde{F C} S_{k} \quad$ Fixed cost for establishing distribution facility in area $\mathrm{k}$

$\widetilde{V C} J_{f s} \quad$ Unit variable cost for cultivating JCL in area $\mathrm{f}$ in scenario $\mathrm{s}$

$\widetilde{V C N}_{n s} \quad$ Unit variable cost for cultivating SL in area $\mathrm{n}$ in scenario s

$\widetilde{V C C}_{i t s} \quad$ Unit variable cost of oil extracting facility $\mathrm{i}$ at year $\mathrm{t}$ in scenario $\mathrm{s}$

$\widetilde{V C B}_{j t s} \quad$ Unit variable cost of biorefinery $\mathrm{j}$ at year $\mathrm{t}$ in scenario $\mathrm{s}$

$\widetilde{V C} S_{k t s} \quad$ Unit variable cost of distriution facility $\mathrm{k}$ at year $\mathrm{t}$ in scenario $\mathrm{s}$

$\widetilde{P C} J_{f t s} \quad$ Unit cost for producing JCL products in area $\mathrm{f}$ at year $\mathrm{t}$ in scenario $\mathrm{s}$

$\widetilde{P C N}_{n t s} \quad$ Unit cost for producing SL products in area $\mathrm{n}$ at year $\mathrm{t}$ in scenario $\mathrm{s}$

$\widetilde{P C C}_{g t s} \quad$ Unit cost for collecting WCO from supply center $\mathrm{g}$ at year $\mathrm{t}$ in scenario $\mathrm{s}$

$\widetilde{P C O}_{i t s} \quad$ Unit cost for extracting oil from JCL products at oil extraction facility $i$ at year $\mathrm{t}$ in scenario $\mathrm{s}$

$\widetilde{P C O N}_{i t s} \quad$ Unit cost for extracting oil from SL products at oil extraction facility $i$ at year $\mathrm{t}$ in scenario $\mathrm{s}$ 


\begin{tabular}{|c|c|}
\hline$\widetilde{P C W}_{j t s}$ & Unit cost for pre-treatmenting $\mathrm{WCO}$ at biorefinery $\mathrm{j}$ at year $\mathrm{t}$ in scenario $\mathrm{s}$ \\
\hline$\overline{P C B}_{j t s}$ & Unit cost for producing biodiesel at biorefinery $j$ at year $t$ in scenario $s$ \\
\hline$\widetilde{I C J}_{i t s}$ & $\begin{array}{l}\text { Cost of holding inventory of JCL products at oil extracting facility } i \text { at year } t \text { in } \\
\text { scenario s }\end{array}$ \\
\hline$\widetilde{C N}_{i t s}$ & $\begin{array}{l}\text { Cost of holding inventory of SL products at oil extracting facility } i \text { at year } t \text { in } \\
\text { scenario s }\end{array}$ \\
\hline$\widetilde{I C B_{j t s}}$ & Cost of holding inventory of biodiesel at biorefinery $\mathrm{j}$ at year $\mathrm{t}$ in scenario $\mathrm{s}$ \\
\hline$\widetilde{I C S} S_{k t s}$ & Cost of holding inventory of biodiesel at distribution facility $\mathrm{k}$ at year $\mathrm{t}$ in scenario $\mathrm{s}$ \\
\hline$\widetilde{J C T}_{\text {flits }}$ & $\begin{array}{l}\text { Cost of transporting JCL products between JCL planting site } \mathrm{f} \text { and oil extracting } \\
\text { facility } \mathrm{i} \text { via mode } 1 \text { at year } \mathrm{t} \text { in scenario } \mathrm{s}\end{array}$ \\
\hline$\overline{N C T}_{\text {nlits }}$ & $\begin{array}{l}\text { Cost of transporting SL products between SL planting site } n \text { and oil extracting } \\
\text { facility i via mode } 1 \text { at year } t \text { in scenario s }\end{array}$ \\
\hline$\overline{W C T}_{g l j t s}$ & $\begin{array}{l}\text { Cost of transporting WCO between supplier } \mathrm{g} \text { and biorefinery } \mathrm{j} \text { via mode } 1 \text { at year } \mathrm{t} \\
\text { in scenario s }\end{array}$ \\
\hline$\widetilde{O C T}_{i l j t s}$ & $\begin{array}{l}\text { Cost of transporting JCL oil between oil extracting facility } i \text { and biorefinery } j \text { via } \\
\text { mode } 1 \text { at year } t \text { in scenario } s\end{array}$ \\
\hline$\widetilde{O N C}_{\text {iljts }}$ & $\begin{array}{l}\text { Cost of transporting SL oil between oil extracting facility } i \text { and biorefinery } j \text { via } \\
\text { mode } 1 \text { at year } t \text { in scenario } s\end{array}$ \\
\hline$\overline{C T}_{j l k t s}$ & $\begin{array}{l}\text { Cost of transporting biodiesel between biorefinery } \mathrm{j} \text { and distribution facility } \mathrm{k} \text { via } \\
\text { mode } 1 \text { at year } \mathrm{t} \text { in scenario } \mathrm{s}\end{array}$ \\
\hline & $\begin{array}{l}\text { Cost of transporting biodiesel between distribution facility } \mathrm{k} \text { and customer } \mathrm{m} \text { via } \\
\text { mode } 1 \text { at year } \mathrm{t} \text { in scenario } \mathrm{s}\end{array}$ \\
\hline
\end{tabular}

\section{Environmental parameters}

$\widetilde{E C J} \quad$ Environmental impact of cultivating each unit of JCL products

$\widetilde{E C N} \quad$ Environmental impact of cultivating each unit of SL products

$\widetilde{E C B} \quad$ Environmental impact of openning each unit capacity of biorefinery

$\widetilde{E C O} \quad$ Environmental impact of openning each unit capacity of oil extraction facility

$\widetilde{E C K} \quad$ Environmental impact of openning each unit capacity of distribution facility

$\widetilde{E O} \quad$ Environmental impact of producing each unit of JCL oil at oil extracting facility

$\widetilde{E O N} \quad$ Environmental impact of producing each unit of SL oil in oil extracting facility

$\widetilde{E B} \quad$ Environmental impact of producing each unit of biodiesel in biorefinery 


\begin{tabular}{|c|c|}
\hline$\widetilde{E J T} T_{f l i}$ & $\begin{array}{l}\text { Environmental impact of transporting each unit of JCL products between JCL } \\
\text { planting site } f \text { and oil extracting facility } i \text { via mode } 1\end{array}$ \\
\hline$\widetilde{E N T}_{n l i}$ & $\begin{array}{l}\text { Environmental impact of transporting each unit of SL products between SL planting } \\
\text { site } n \text { and oil extracting facility } i \text { via mode } 1\end{array}$ \\
\hline$\overline{E W T}_{g l j}$ & $\begin{array}{l}\text { Environmental impact of transporting each unit of WCO between supplier } g \text { and } \\
\text { biorefinery } j \text { via mode } 1\end{array}$ \\
\hline$\widetilde{E O T}_{i l j}$ & $\begin{array}{l}\text { Environmental impact of transporting each unit of JCL oil between oil extracting } \\
\text { facility } i \text { and biorefinery } j \text { via mode } 1\end{array}$ \\
\hline$\widetilde{E O N T}_{i l j}$ & $\begin{array}{l}\text { Environmental impact of transporting each unit of SL oil between oil extracting } \\
\text { facility } i \text { and biorefinery } j \text { via mode } 1\end{array}$ \\
\hline$\overline{E B T}_{j l k}$ & $\begin{array}{l}\text { Environmental impact of transporting each unit of biodiesel between biorefinery } \mathrm{j} \\
\text { and distribution facility } \mathrm{k} \text { via mode } \mathrm{l}\end{array}$ \\
\hline$\widetilde{E M T}_{j l k}$ & $\begin{array}{l}\text { Environmental impact of transporting each unit of biodiesel between biorefinery } \mathrm{j} \\
\text { and distribution facility } \mathrm{k} \text { via mode } \mathrm{l}\end{array}$ \\
\hline$\widetilde{E I J}$ & $\begin{array}{l}\text { Environmental impact of holding inventory each unit of JCL products in oil } \\
\text { extracting facility }\end{array}$ \\
\hline$\widetilde{E I N}$ & $\begin{array}{l}\text { Environmental impact of holding inventory each unit of SL products in oil } \\
\text { extracting facility }\end{array}$ \\
\hline$\widetilde{E I B}$ & Environmental impact of holding inventory per unit of biodiesel in biorefinery \\
\hline$\widetilde{E I S}$ & $\begin{array}{l}\text { Environmental impact of holding inventory per unit of biodiesel in distribution } \\
\text { facility }\end{array}$ \\
\hline
\end{tabular}

\section{Decision variables} otherwise
$y_{n}$ Binary variable assuming value of 1 if area $\mathrm{n}$ is chosen for SL cultivation, and 0 otherwise
Binary variable assuming value of 1 if area $i$ is chosen for establishing oil extraction
$u_{i}$ facility, and 0 otherwise
Binary variable assuming value of 1 if area $\mathrm{j}$ is chosen for establishing biorefinery at $v_{j t} \quad$ year $\mathrm{t}$, and 0 otherwise
$w_{k}$ Binary variable assuming value of 1 if area $\mathrm{k}$ is chosen for establishing distribution facility, and 0 otherwise

Binary variable assuming value of 1 if area $\mathrm{f}$ is chosen for JCL cultivation, and 0 


\begin{tabular}{|c|c|}
\hline$C O_{p j t}$ & $\begin{array}{l}\text { Binary variable assuming value of } 1 \text { if capacity } \mathrm{p} \text { selected to biorefinery } \mathrm{j} \text { at year } \mathrm{t} \text {, } \\
\text { and } 0 \text { otherwise }\end{array}$ \\
\hline$I J_{i t s}$ & JCL products inventory level at oil extraction facility $i$ at year $t$ in scenario $s$ \\
\hline$I N_{i t s}$ & SL products inventory level at oil extraction facility $i$ at year $t$ in scenario $s$ \\
\hline$I B_{j t s}$ & Biodiesel inventory level at biorefinery $\mathrm{j}$ at year $\mathrm{t}$ in scenario $\mathrm{s}$ \\
\hline$I S_{k t s}$ & Biodiesel inventory level at distribution facility $\mathrm{k}$ at year $\mathrm{t}$ in scenario $\mathrm{s}$ \\
\hline$P J_{f t s}$ & Quantity of produced JCL at JCL cultivation area $f$ at year $t$ in scenario $s$ \\
\hline$P N_{n t s}$ & Quantity of produced SL at SL cultivation area $n$ at year $t$ in scenario $s$ \\
\hline$P O_{i t s}$ & Quantity of produced JCL oil at oil extracting facility i at year $t$ in scenario s \\
\hline$P O N_{i t s}$ & Quantity of produced SL oil at oil extracting facility $i$ at year $t$ in scenario $s$ \\
\hline$P W_{j t s}$ & Quantity of produced pre-treated WCO at biorefinery $\mathrm{j}$ at year $\mathrm{t}$ in scenario $\mathrm{s}$ \\
\hline$P B_{j t s}$ & Quantity of produced biodiesel in biorefinery $\mathrm{j}$ at year $\mathrm{t}$ in scenario $\mathrm{s}$ \\
\hline$S H_{m t s}$ & Quantity of unsatisfied demand of consumer $m$ at year $t$ in scenario $s$ \\
\hline$J T_{\text {flits }}$ & $\begin{array}{l}\text { Quantity of JCL products shipped from JCL planting site f to oil extracting facility i } \\
\text { via mode } 1 \text { at year } t \text { in scenario } s\end{array}$ \\
\hline$N T_{\text {nlits }}$ & $\begin{array}{l}\text { Quantity of SL products shipped from SL planting site } n \text { to oil extracting facility } i \\
\text { via mode } 1 \text { at year } t \text { in scenario s }\end{array}$ \\
\hline $\mathrm{WT}_{\text {gljts }}$ & $\begin{array}{l}\text { Quantity of WCO shipped from supplier } g \text { to biorefinery } j \text { via mode } 1 \text { at year } t \text { in } \\
\text { scenario s }\end{array}$ \\
\hline$O T_{i l j t s}$ & $\begin{array}{l}\text { Quantity of JCL oil shipped from oil extracting facility i to biorefinery } \mathrm{j} \text { via mode } 1 \\
\text { at year } \mathrm{t} \text { in scenario s }\end{array}$ \\
\hline$O N T_{\text {iljts }}$ & $\begin{array}{l}\text { Quantity of SL oil shipped from oil extracting facility i to biorefinery } j \text { via mode } 1 \text { at } \\
\text { year } t \text { in scenario s }\end{array}$ \\
\hline$B T_{j l k t s}$ & $\begin{array}{l}\text { Quantity of biodiesel shipped from biorefinery } \mathrm{j} \text { to distribution facility } \mathrm{k} \text { via mode } 1 \\
\text { at year } \mathrm{t} \text { in scenario } \mathrm{s}\end{array}$ \\
\hline$M T_{k l m t s}$ & $\begin{array}{l}\text { Quantity of biodiesel shipped from distribution facility } \mathrm{k} \text { to customer } \mathrm{m} \text { via mode } 1 \\
\text { at year } \mathrm{t} \text { in scenario } \mathrm{s}\end{array}$ \\
\hline$C J_{f}$ & Total cultivated land of JCL in area $\mathrm{f}$ \\
\hline$C N_{n}$ & Total cultivated land of SL in area $n$ \\
\hline$C C_{i t}$ & Total capacity of oil extracting facility $\mathrm{i}$ at year $\mathrm{t}$ \\
\hline$C E C_{i t}$ & Quantity of capacity expansion in oil extracting facility $\mathrm{i}$ at year $\mathrm{t}$ \\
\hline$C B_{j t}$ & Total capacity of biorefinery $\mathrm{j}$ at year $\mathrm{t}$ \\
\hline$C S_{k t}$ & Total capacity of distribution facility $\mathrm{k}$ at year $\mathrm{t}$ \\
\hline
\end{tabular}


$C E S_{k t} \quad$ Amount of expansion of capacity at distribution facility k at year $\mathrm{t}$

\section{3-2- Constraints}

Constraint (1) guarantees that the quantity of biodiesel shipped from the biorefineries to a city is at least equal to its corresponding demand. Equation (2) indicates the maximum amount of possible shortage. Constraints (3) to (5) ensure that all JCL, SL and WCO will be shipped to their corresponding facilities.

$$
\begin{array}{lc}
\sum_{k} \sum_{l} M T_{k l m t s}+S H_{m t s} \geq \widetilde{D}_{m t s} \forall m, t, s \\
S H_{m t s} \leq(1-c s l) \widetilde{D}_{m t s} \quad \forall m, t, s \\
\sum_{l} \sum_{i} J T_{\text {flits }}=P J_{f t s} \quad \forall f, t, s \\
\sum_{l} \sum_{i} N T_{\text {nlits }}=P N_{n t s} \quad \forall n, t, s \\
\sum_{l} \sum_{j} W T_{g l j t s} \leq \widetilde{W O}_{g t s} \quad \forall g, t, \mathrm{~s}
\end{array}
$$

Constraints (6) and (7) represent the quantity of JCL and SL yields in the cultivated areas in each period. Equations (8) to (11) indicate the quantity of extracted JCL oil, extracted SL oil, pre-treated WCO, and produced biodiesel, respectively.

$$
\begin{array}{ll}
P J_{f t s}=\eta_{f t} C J_{f} & \forall f, t, s \\
P N_{n t s}=\tau C N_{n} \quad \forall n, t & \\
P O_{i t s}=\theta \sum_{f} \sum_{l} J T_{f l i t s} \quad \forall i, t, s \\
P O N_{i t s}=\varphi \sum_{n} \sum_{l} N T_{\text {nlits }} & \forall i, t, s \\
P W_{j t s}=\beta \sum_{g} \sum_{l} W T_{\text {gljts }} & \forall j, t, s
\end{array}
$$




$$
P B_{j t s}=\gamma \sum_{i} \sum_{l} O T_{i l j t s}+\Delta \sum_{i} \sum_{l} O N T_{i l j t s}+\omega P W_{j t s} \quad \forall j, t, s
$$

Constraint (12) represents that the level of inventory of JCL products at oil extracting facilities in each period of time is equal to the level of inventory in the previous period, in addition to the quantities of JCL shipped to these centers, minus the quantities of JCL converted to JCL oil that transported to biorefineries. Also, Equation (13) shows the level of inventory in oil extraction centers for SL products. Finally, constraints (14) and (15) indicate the level of inventory balance in refineries and distribution centers, respectively.

$$
\begin{aligned}
& I J_{i t s}=I J_{i, t-1, s}+\sum_{f} \sum_{l} J T_{\text {flits }}-\left(\frac{1}{\theta}\right) \sum_{l} \sum_{j} O T_{i l j t s} \quad \forall i, t, s \\
& I N_{i t s}=I N_{i, t-1, s}+\sum_{n} \sum_{l} N T_{\text {nlits }}-\left(\frac{1}{\varphi}\right) \sum_{l} \sum_{j} O N T_{i l j t s} \quad \forall i, t, s \\
& I B_{j t s}=I B_{j, t-1, s}+P B_{j t s}-\sum_{l} \sum_{k} B T_{j l k t s} \forall j, t, s \\
& I S_{k t s}=I S_{k, t-1, s}+\sum_{j} \sum_{l} B T_{j l k t s}-\sum_{l} \sum_{m} M T_{k l m t s} \quad \forall k, t, s
\end{aligned}
$$

Constraint (16) represents a logical expression. Constraint (17) guaranties that when a biorefinery is established, it will be active up to the end of time horizon. Similarly, constraint (18) guaranties that when a capacity option is added to a refinery, it will be active up to the end of time period.

Equations (19) and (20) state the maximum and minimum permissible locations for cultivating of JCL and SL. Constraints (21) to (23) represent the maximum and minimum capacities of oil extracting facilities, biorefineries and distribution centers, respectively.

Equations (24) and (25) state the minimum number of JCL and SL cultivation centers, respectively. Constraints (26) and (27) show the amount of capacity added to each of the oil extraction facilities and distribution facilities, respectively. Equation (28) calculates total capacity of refineries over the planning horizon.

$$
C O_{p j t} \leq v_{j t} \quad \forall p, j, t
$$




$$
\begin{aligned}
& v_{j t} \leq v_{j(t+1) \quad} \quad \forall j, t \\
& C O_{p j t} \leq C O_{p j(t+1)} \quad \forall p, j, t \\
& x_{f} L A_{f} \leq C J_{f} \leq x_{f} U A_{f} \quad \forall f \\
& y_{n} L N_{n} \leq C N_{n} \leq y_{n} U N_{n} \quad \forall n \\
& u_{i} L C_{i} \leq C C_{i t} \leq u_{i} U C_{i} \quad \forall i, t \\
& v_{j t} L B_{j} \leq C B_{j t} \leq v_{j t} U B_{j} \quad \forall j, t \\
& w_{k} L S_{k} \leq C S_{k t} \leq w_{k} U S_{k} \quad \forall k, t \\
& \sum_{f} x_{f} \geq M i n x \\
& \sum_{n} y_{n} \geq M i n y \\
& C C_{i t}=C C_{i, t-1}+C E C_{i t} \quad \forall i, t \\
& C S_{k t}=C S_{k, t-1}+C E S_{k t} \quad \forall k, t \\
& C B_{j \mathrm{jt}}=C B_{\mathrm{j}, \mathrm{t}-1}+C W_{j t}\left(v_{j t}-v_{j, t-1}\right)+\sum_{p} R_{p j t} C O_{p j t} \quad \forall j, t
\end{aligned}
$$

Constraints (29) to (31) guaranty that the amount of products shipped to each facility does not exceed the capacity of that facility. Constraints (32) to (34) state that the inventory in each facility should not be more than its corresponding capacity.

$\sum_{f} \sum_{l} J T_{\text {flits }}+\sum_{n} \sum_{l} N T_{\text {nlits }} \leq C C_{i t} \quad \forall i, t, s$ 


$$
\begin{aligned}
& \sum_{i} \sum_{l} O T_{i l j t s}+\sum_{i} \sum_{l} O N T_{i l j t s}+\sum_{g} \sum_{l} W T_{g l j t s} \leq C B_{j t} \quad \forall j, t, s \\
& \sum_{j} \sum_{l} B T_{j l k t s} \leq C S_{k t} \quad \forall k, t, s \\
& I J_{i t s}+I N_{i t s} \leq C C_{i t} \quad \forall i, t, s \\
& I B_{j t s} \leq C B_{j t} \quad \forall j, t, s \\
& I S_{k t s} \leq C S_{k t} \quad \forall k, t
\end{aligned}
$$

Finally, constraints (35) and (36) state the binary and non-negativity natures of the decision variables, respectively.

$$
x_{f}, y_{n}, u_{i}, v_{j t}, C O_{p j t}, w_{k} \in\{0,1\}
$$

Continuous decision variables $\geq 0$

\section{3-3- Objective functions}

The first presented objective function minimizes the total costs, like the fixed costs of establishing the facilities (FC), the variable costs of establishing the facilities (VC), the production costs (PC), the inventory holding costs (IC) and the transportation costs among facilities (TC).

$$
\begin{aligned}
\widetilde{F C}=\sum_{f} \widetilde{F C} J_{f} x_{f} & +\sum_{n} \widetilde{F C N}_{n} y_{n}+\sum_{i} \widetilde{F C C_{i} u_{i}}+\sum_{j} \sum_{t} \widetilde{F C B}_{j}\left(v_{j t}-v_{j, t-1}\right) \\
& +\sum_{k} \widetilde{F C S_{k} w_{k}}
\end{aligned}
$$




$$
\begin{aligned}
& \widetilde{V C}_{s}=\sum_{f} \widetilde{V C} J_{f s} C J_{f}+\sum_{n} \widetilde{V C N}_{n s} C N_{n}+\sum_{i} \sum_{t} \widetilde{V C C}_{i t s} C C_{i t} \\
& +\sum_{j} \sum_{t} \widetilde{V C B}_{j t s} C B_{j t}+\sum_{k} \sum_{t} \widetilde{V C} S_{k t s} C S_{k t} \quad \forall s \\
& \widetilde{P C}_{s}=\sum_{f} \sum_{t} \widetilde{P C} J_{f t s} P J_{f t s}+\sum_{n} \sum_{t} \widetilde{P C N}_{n t s} P N_{n t s}+\sum_{g} \sum_{t} \widetilde{P C C}_{g t s} W O_{g t s} \\
& +\sum_{i} \sum_{t} \widetilde{P C O}_{i t s} P_{i t s}+\sum_{i} \sum_{t} \widetilde{P C O N}_{i t s} P O_{i t s} \\
& +\sum_{j}^{i} \sum_{t}^{t} \widetilde{P C W}_{j t s} P W_{j t s}+\sum_{j}^{i} \sum_{t}^{t} \widetilde{P C B}_{j t s} P B_{j t s} \quad \forall s \\
& \widetilde{I C}_{s}=\sum_{i} \sum_{t} \widetilde{I C J}_{i t s} I J_{i t s}+\sum_{i} \sum_{t} I \widetilde{C N} \widetilde{I t s}_{i N_{i t s}}+\sum_{j} \sum_{t} \widetilde{I C B_{j t s}} I B_{j t s} \\
& +\sum_{k} \sum_{t} \widetilde{I C S} S_{k t s} I S_{k t s} \quad \forall s \\
& \widetilde{T C}_{s}=\sum_{f} \sum_{l} \sum_{i} \sum_{t} \widetilde{J C T_{\text {flits }}} J T_{\text {flits }}+\sum_{n} \sum_{l} \sum_{i} \sum_{t}{\widetilde{N C T_{\text {nlits }}}}_{t} N T_{\text {nlits }} \\
& +\sum_{g} \sum_{l} \sum_{j} \sum_{t} \widetilde{W C T}_{g l j t s} W T_{g l j t s} \\
& +\sum_{i} \sum_{l} \sum_{j} \sum_{t}{\widetilde{O C T_{i l j t s}}}_{i l j t s} \\
& +\sum_{i} \sum_{l} \sum_{j} \sum_{t} \widetilde{O N C}_{i l j t s} O N T_{i l j t s} \\
& +\sum_{j} \sum_{l} \sum_{k} \sum_{t} \widetilde{B C T}_{j l k t s} B T_{j l k t s} \\
& +\sum_{k} \sum_{l} \sum_{m} \sum_{t} \widetilde{M C T}_{k l m t s} M T_{k l m t s} \quad \forall s
\end{aligned}
$$

So, according to the above terms, the cost objective function can be formulated as by equation (42): 
$\operatorname{Min} Z_{1}=\widetilde{F C}+\sum_{s} p_{s}\left(\widetilde{V C}_{s}+\widetilde{P C}_{s}+\widetilde{I C}_{s}+\widetilde{T C}_{s}\right)$

The second presented objective function minimizes the total environmental impact of opening the facilities (EF), production (EP), inventory holding (EI) and transportation (ET).

$$
\begin{gathered}
\widetilde{E F}=\sum_{f} \widetilde{E C J C J_{f}}+\sum_{n} \widetilde{E C N} C N_{n}+\sum_{i} \sum_{t} \widetilde{E C O C} C_{i t}+\sum_{j} \sum_{t} \widetilde{E C B} C B_{j t} \\
+\sum_{k} \sum_{t} \widetilde{E C K} C S_{k t}
\end{gathered}
$$

$$
\widetilde{E P}=\sum_{i} \sum_{t} \widetilde{E O} P O_{i t s}+\sum_{i} \sum_{t} \widetilde{E O N} P O N_{i t s}+\sum_{j} \sum_{t} \widetilde{E B} P B_{j t s} \quad \forall s
$$

$$
\begin{gathered}
\widetilde{E I}_{s}=\sum_{i} \sum_{t} \widetilde{E I J} I J_{i t s}+\sum_{i} \sum_{t} \widetilde{E I N} I N_{i t s}+\sum_{j} \sum_{t} \widetilde{E I B} I B_{j t s} \\
+\sum_{k} \sum_{t} \widetilde{E I S} I S_{k t s} \quad \forall s
\end{gathered}
$$

$$
\begin{aligned}
& \widetilde{E T}_{s}=\sum_{f} \sum_{l} \sum_{i} \sum_{t} \widetilde{E J T}_{f l i} D J T_{f l i} J T_{f l i t s}+\sum_{n} \sum_{l} \sum_{i} \sum_{t} \widetilde{E N T}_{n l i} D N T_{n l i} N T_{n l i t s} \\
& +\sum_{g} \sum_{l} \sum_{j} \sum_{t} \widetilde{E W T}_{g l j} D W T_{g l j} W T_{g l j t s} \\
& +\sum_{i} \sum_{l} \sum_{j} \sum_{t} \widetilde{E O T}_{i l j}{ }{ } O T_{i l j} O T_{i l j t s} \\
& +\sum_{i} \sum_{l} \sum_{j} \sum_{t} \widetilde{E O N T}_{i l j}{ }_{\text {DOT }}{ }_{i l j} O N T_{i l j t s} \\
& +\sum_{j} \sum_{l} \sum_{k} \sum_{t} \widetilde{E B T}_{j l k} D B T_{j l k} B T_{j l k t s} \\
& +\sum_{k} \sum_{l} \sum_{m} \sum_{t} \widetilde{E M T}_{j l k} D M T_{k l m} M T_{k l m t s} \quad \forall s
\end{aligned}
$$


Similarly, according to the above terms, the Environmental objective function can be formulated by Equation (47):

$$
\operatorname{Min} Z_{2}=\widetilde{E F}+\sum_{s} p_{s}\left(\widetilde{E P}_{s}+\widetilde{E I}_{s}+\widetilde{E T}_{s}\right)
$$

\section{3-4- Multi-objective approach}

Many methods have been presented in the literature for solving multi-objective optimization problems. One of these methods is bounded objective function (BOF) method. In this approach, a problem with several objective functions converts to a single-objective problem. In the BOF method, the minimum and maximum values of objective function $F_{i}$ are determined by the decision maker and are represented by $\mathrm{L}^{\mathrm{i}}$ and $\mathrm{U}^{\mathrm{i}}$, respectively.

As shown in Equations (48)-(50), in this method, the most important objective function, i.e. $\mathrm{F}_{\mathrm{r}}(\mathrm{X})$, is minimized and other objective functions are placed in constraints and a high and low limit is considered for them. By changing the values of $\mathrm{L}^{\mathrm{i}}$ and $\mathrm{U}^{\mathrm{i}}$, the Pareto frontiers of the problem can be obtained.

$\operatorname{Min} F_{r}(X)$

S.t.

$g_{i} \leq 0 \quad \forall j$

$L^{i} \leq F_{i}(X) \leq U^{i} \quad \forall i, \quad i \neq r$

\section{4- The proposed robust fuzzy stochastic programming approach}

In this section the presented robust fuzzy stochastic programming (RFSP) model is defined. The presented model is based on the robust scenario-based programming model and fuzzy possibilistic programming model. The proposed RFSP model can consider hybrid uncertainties.

Consider the following mathematical model.

$\operatorname{Min} \tilde{f} x+\tilde{c}_{s} y_{s}$

$A y_{s} \geq \tilde{d}_{s}$

$B x=0$ 


$$
D y_{s} \leq \tilde{e}_{s}
$$

$x \in\{0,1\}, \quad y_{s} \geq 0$

Where $\tilde{f}$ has fuzzy nature, $\tilde{c}_{s}, \tilde{d}_{s}$, and $\tilde{e}_{s}$ have fuzzy scenario nature. The general model of fuzzy stochastic programming is as follows:

$$
\begin{aligned}
& \text { Min } F+\lambda v(\tilde{F})+\gamma \sum_{s} p_{s} \theta_{s}+\omega \sum_{s} p_{s} S H_{m t s} \pi_{m t s} \\
& A y_{s} \geq(2-2 \alpha) d_{s}^{2}+(2 \alpha-1)\left(d_{s}^{2}+d_{s}^{4}\right) \\
& B x=0 \\
& D y_{s} \leq(2 \alpha-1)\left(e_{s}^{1}-e_{s}^{3}\right)+(2-2 \alpha) e_{s}^{1} \\
& \left(\frac{\left(F^{1}-\frac{1}{3} F^{3}-F_{s}^{2}\right)+\left(F^{2}+\frac{1}{3} F^{4}-F_{s}^{1}\right)}{2}+\frac{F_{s}^{4}-F_{s}^{3}}{6}\right)+\theta_{s} \geq 0 \quad \forall s \\
& \left(\frac{\left(F_{s}^{1}-F^{2}-\frac{1}{3} F^{4}\right)+\left(F_{s}^{2}-F^{1}+\frac{1}{3} F^{3}\right)}{2}+\frac{F_{s}^{3}-F_{s}^{4}}{6}\right)+\theta_{s} \geq 0 \quad \forall s \\
& x \in\{0,1\}, \quad y_{s} \geq 0
\end{aligned}
$$

As Equation (56) shows, the objective function is composed of several components, which are as follows:

- The weighted possibilistic mean value of the objective function is obtained by Equation (63).

- Possibilistic variability of the objective function is calculted by Equation (64).

- The third term of Equation (56) shows the scenario variability of the objective function.

- Finally, the fourth term of Equation (56) represents the unsatisfied demand costs. 
In Equation (56), $\lambda$ and $\gamma$ represents the weight of possibilistic variability and scenario variability, respectively. $\omega$ is a coefficient that adjust the weighted penalty for possible violation of each constraint.

It should be noted that, if we use trapezoidal fuzzy numbers for expression $\tilde{f} x+\tilde{c}_{s} y_{s}$; i.e. $\widetilde{f}_{l}=\left(f_{i}^{1}, f_{i}^{2}, f_{i}^{3}, f_{i}^{4}\right)$ and $\widetilde{c_{j S}}=\left(c_{j s}^{1}, c_{j s}^{2}, c_{j s}^{3}, c_{j s}^{4}\right), F$ and $v(\widetilde{F})$ are obtained by Equations (63) and (64), respectively.

$$
\begin{aligned}
& F=\sum_{i}\left(\frac{f_{i}^{1}+f_{i}^{2}}{2}+\frac{f_{i}^{4}-f_{i}^{3}}{6}\right) x_{i}+\sum_{j} \sum_{s} p_{s}\left(\frac{c_{j s}^{1}+c_{j s}^{2}}{2}+\frac{c_{j s}^{4}-c_{j s}^{3}}{6}\right) y_{j s} \\
& v(\tilde{F})=\sum_{i}\left(f_{i}^{2}-f_{i}^{1}+\frac{f_{i}^{3}+f_{i}^{4}}{3}\right) x_{i}+\sum_{j} \sum_{s} p_{s}\left(c_{j s}^{2}-c_{j s}^{1}+\frac{c_{j s}^{3}+c_{j s}^{4}}{3}\right) y_{j s}
\end{aligned}
$$

Equations (65) and (66) are also used for constraints (60) and (61):

$$
\begin{aligned}
\widetilde{F}_{s}=\left(\sum_{i} f_{i}^{1} x_{i}\right. & +\sum_{j} c_{j s}^{1} y_{j s}, \sum_{i} f_{i}^{2} x_{i}+\sum_{j} c_{j s}^{2} y_{j s}, \sum_{i} f_{i}^{3} x_{i}+\sum_{j} c_{j s}^{3} y_{j s}, \sum_{i} f_{i}^{4} x_{i} \\
& \left.+\sum_{j} c_{j s}^{4} y_{j s}\right)=\left(F_{s}^{1}, F_{s}^{2}, F_{s}^{3}, F_{s}^{4}\right) \\
\widetilde{F}=\left(\sum_{i} f_{i}^{1} x_{i}\right. & +\sum_{j} \sum_{s} p_{s} c_{j s}^{1} y_{j s}, \sum_{i} f_{i}^{2} x_{i}+\sum_{j} \sum_{s} p_{s} c_{j s}^{2} y_{j s}, \sum_{i} f_{i}^{3} x_{i} \\
& \left.+\sum_{j} \sum_{s} p_{s} c_{j s}^{3} y_{j s}, \sum_{i} f_{i}^{4} x_{i}+\sum_{j} \sum_{s} p_{s} c_{j s}^{4} y_{j s}\right)=\left(F^{1}, F^{2}, F^{3}, F^{4}\right)
\end{aligned}
$$

\section{5- Computational experiments and evaluation}

The presented MORFSP model is applied in a real case to design the BSCN in Iran. The results of solving the presented model are described in this section. The model is coded in GAMS software and solved using CPLEX solving method.

In this study, a 7 years planning horizon for implementing the proposed model is considered. SimaPro 8 software is applied to obtain the environmental impacts of the processes. Considering the fact that at least $80 \%$ of Iran's edible oils are provided by imports, 
it's not logical using edible oil sources for producing biodiesel. Therefore, in this study, JCL and SL that are non-edible plants and compatible with Iran's climate and require little water are selected as biodiesel resources. WCO is also considered as another source of producing biodiesel. The most appropriate locations for cultivation of these plants are considered as the candidate areas, in which 11 and 7 areas are selected for JCL and SL, respectively. In addition, considering the demand of diesel and air pollution problem of the cities (big and industrial cities), 7 cities are selected as biodiesel consumers.

Therefore, in this model 11 candidate areas for cultivation of JCL, 7 potential areas for cultivating SL, 30 potential WCO suppliers, 30 candidate areas for oil extraction facilities, 30 potential areas for biorefineries, 30 candidate areas for distribution facilities, 7 areas for biodiesel consumers, and 2 transportation modes are considered.

In this research, the scenarios and their probability values are obtained based on Pishvaee et al. (2008) and Rezaei et al. (2020b), in which 3 scenarios are designed. The values of the fuzzy and fuzzy stochastic parameters are obtained based on the experts' opinions and according to the structure of the scenarios.

Bounded objective function method is used to solve the presented multi-objective model. In this research, the cost objective function is minimized as the most important objective function, and the environmental objective function is placed in the constraints for different limits. Figure 2 shows the Pareto frontiers for the objectives.

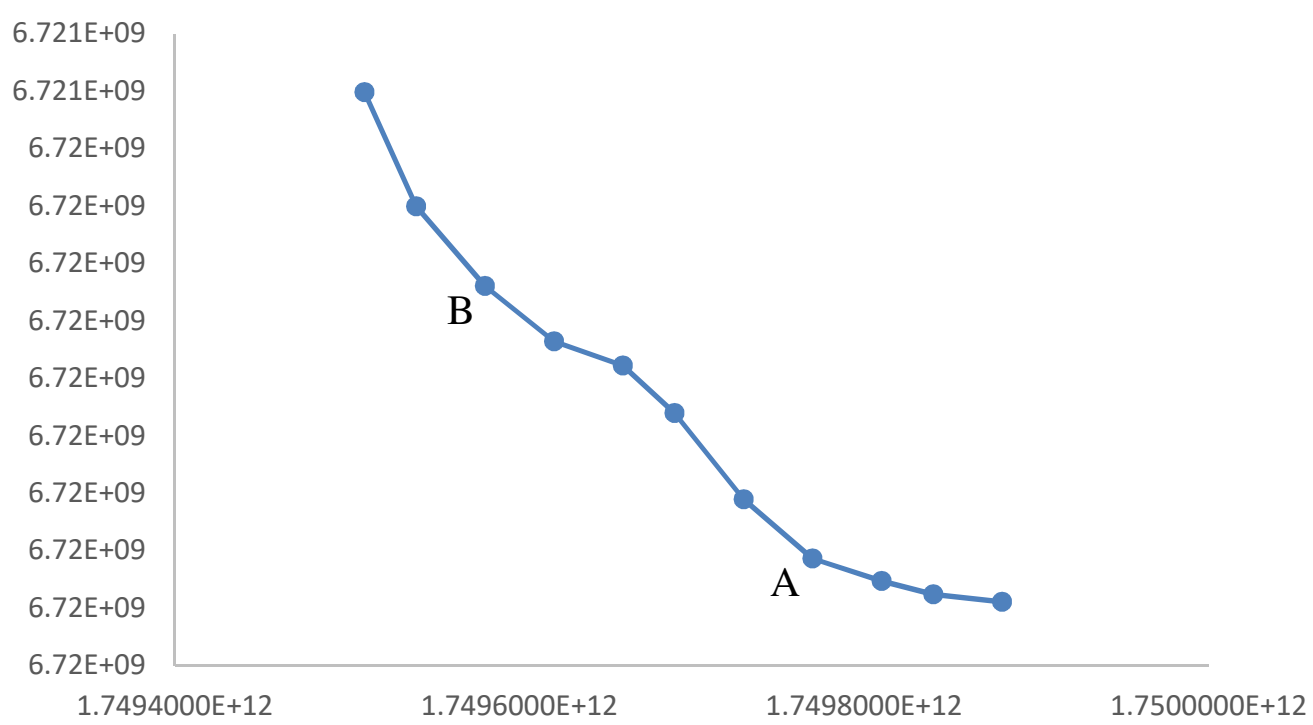

Figure 2. Pareto frontiers for the objectives

As shown in Figure 2, the cost objective function and the environmental objective function are not compatible. Therefore, according to the preferences of the decision maker a point from the Pareto optimal set is selected. The values of the objective functions for the two points of the Pareto optimal set (points A and B) are compared in Table 2. 
Table 2. The values of objective function (million Rials)

\begin{tabular}{|c|c|c|c|c|c|c|c|}
\hline \multirow{2}{*}{ Points } & \multicolumn{4}{|c|}{ Cost objective function } & \multicolumn{3}{c|}{ Environmental objective function } \\
\cline { 2 - 8 } & Mean & $\begin{array}{c}\text { Possibilistic } \\
\text { variability }\end{array}$ & $\begin{array}{c}\text { Scenario } \\
\text { variability }\end{array}$ & $\begin{array}{c}\text { Un- } \\
\text { fulfillment }\end{array}$ & Mean & $\begin{array}{c}\text { Possibilistic } \\
\text { variability }\end{array}$ & $\begin{array}{c}\text { Scenario } \\
\text { variability }\end{array}$ \\
\hline \multirow{2}{*}{ A } & $1.770873 \mathrm{E}+09$ & $1.39389 \mathrm{E}+09$ & $1.87536 \mathrm{E}+09$ & 911647454 & $7.6927 \mathrm{E}+11$ & $6.1052 \mathrm{E}+11$ & $4.31489 \mathrm{E}+10$ \\
\hline \multirow{2}{*}{ B } & $1.770859 \mathrm{E}+09$ & $1.39387 \mathrm{E}+09$ & $1.87535 \mathrm{E}+09$ & 914917764 & $7.6919 \mathrm{E}+11$ & $6.1045 \mathrm{E}+11$ & $4.31433 \mathrm{E}+10$ \\
\hline
\end{tabular}

Also the different components of the objective functions for these points are summarized in Table 3.

Table 3. The components of the objective function (million Rials)

\begin{tabular}{|c|c|c|c|c|c|c|c|c|c|}
\hline \multirow{2}{*}{ Points } & \multicolumn{5}{|c|}{ Cost objective function } & \multicolumn{4}{|c|}{ Environmental objective function } \\
\hline & Fixed & Variable & Production & $\begin{array}{r}\text { Inventory } \\
\text { holding }\end{array}$ & Transportation & $\begin{array}{l}\text { Construction } \\
\text { and capacity }\end{array}$ & Production & $\begin{array}{r}\text { Inventory } \\
\text { holding }\end{array}$ & Transportation \\
\hline $\mathbf{A}$ & 56537 & $1.25091 \mathrm{E}+09$ & $4.40988 \mathrm{E}+08$ & 4228309 & 74686682 & 7.6409E+11 & $5.1440 \mathrm{E}+09$ & 26429629 & 7138994 \\
\hline B & 56537 & $1.25088 \mathrm{E}+09$ & 4.41113E+08 & 4209219 & 74597988 & $7.6401 \mathrm{E}+11$ & $5.1430 \mathrm{E}+09$ & 26300372 & 7195114 \\
\hline
\end{tabular}

In the following, the optimal location of each facility and their capacities, which have been obtained by solving the model, are described. It should be noted that these items are related to point $\mathrm{A}$.

The optimal locations for Jatropha cultivation and the capacity of each of these areas are shown in Figure 3.

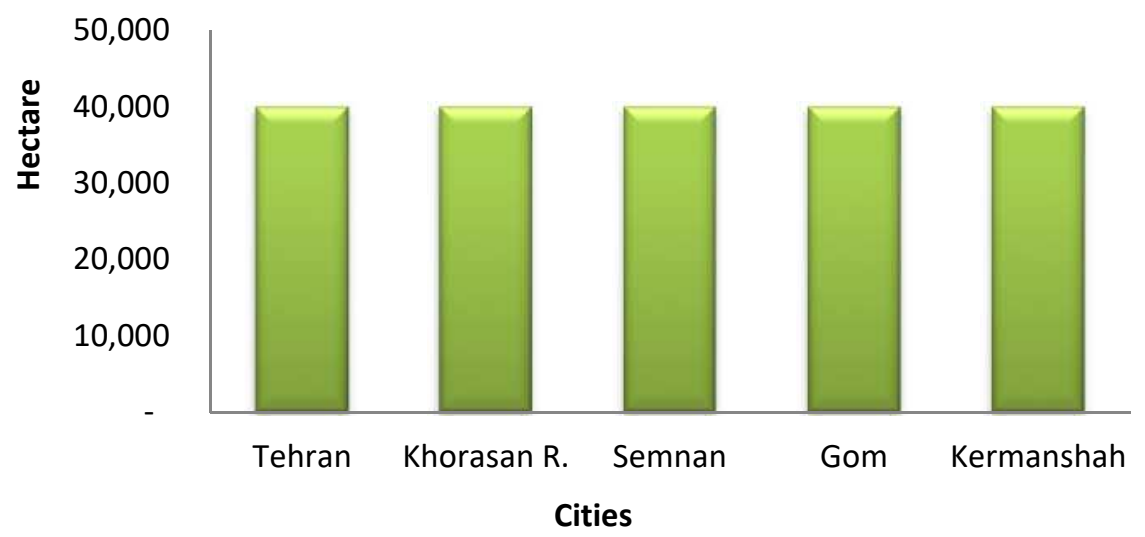

Figure 3. Jatropha cultivation areas and their capacities

Similarly, suitable locations for cultivating Noruzak and their capacities are shown in Figure 4. 


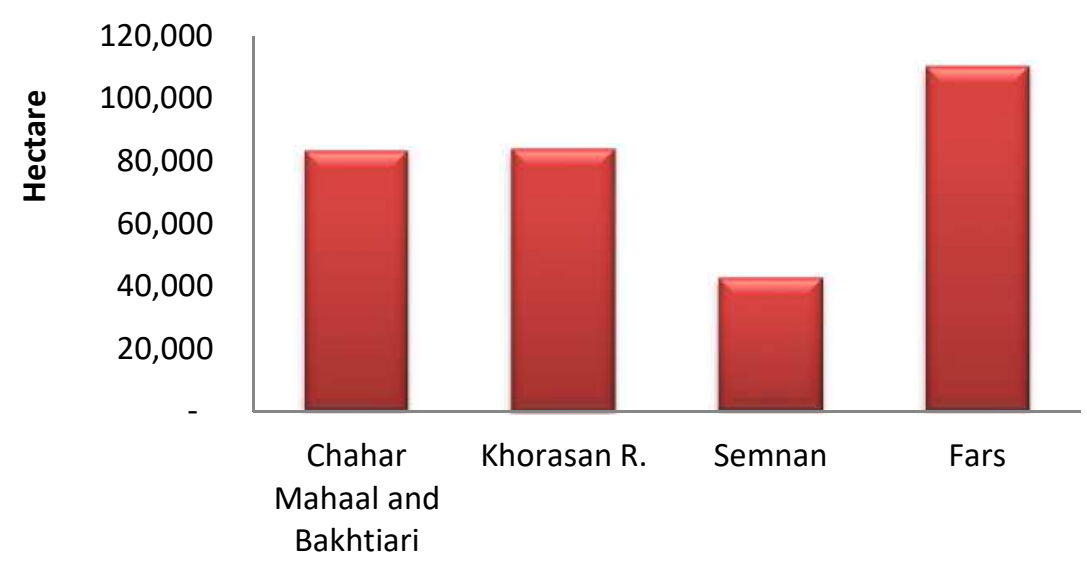

Cities

Figure 4. SL cultivation areas and their capacities

The optimal areas for opening oil extraction facilities and biorefinery centers and their corresponding capacities are shown in Tables 4 and 5, respectively.

Table 4. Established oil ectraction centers and their capacities

\begin{tabular}{|c|c|c|c|c|c|c|c|}
\hline \multirow{2}{*}{ Cities } & \multicolumn{7}{|c|}{ Year } \\
\cline { 2 - 8 } & 1 & 2 & 3 & 4 & 5 & 6 & 7 \\
\hline Tehran & 20000 & 60000 & 120000 & 160000 & 200000 & 200000 & 200000 \\
\hline $\begin{array}{c}\text { Chahar } \\
\text { Mahaal and } \\
\text { Bakhtiari }\end{array}$ & 640861 & 640861 & 640861 & 640861 & 640861 & 640861 & 640861 \\
\hline Khorasan R. & 667027 & 707027 & 767027 & 807027 & 847027 & 847027 & 847027 \\
\hline Semnan & 349182 & 389182 & 449182 & 449182 & 529182 & 529182 & 781747 \\
\hline Fars & 849459 & 849459 & 849459 & 849459 & 849459 & 849459 & 849459 \\
\hline Gom & 20000 & 60000 & 120000 & 160000 & 200000 & 200000 & 200000 \\
\hline Kermanshah & 20000 & 60000 & 120000 & 160000 & 200000 & 200000 & 338528 \\
\hline Sum & 2566529 & 2766529 & 3066529 & 3226529 & 3466529 & 3466529 & 3857622 \\
\hline
\end{tabular}

Table 5. Established biorefinery centers and their capacities

\begin{tabular}{|c|c|c|c|c|c|c|c|}
\hline \multirow{2}{*}{ Cities } & \multicolumn{7}{|c|}{ Year } \\
\cline { 2 - 8 } & 1 & 2 & 3 & 4 & 5 & 6 & 7 \\
\hline Tabriz & 106000 & 206000 & 306000 & 406000 & 506000 & 606000 & 706000 \\
\hline Isfahan & 120000 & 220000 & 320000 & 420000 & 520000 & 620000 & 720000 \\
\hline Tehran & 105000 & 205000 & 305000 & 405000 & 505000 & 605000 & 705000 \\
\hline Khorasan R. & 110000 & 215000 & 320000 & 425000 & 530000 & 635000 & 740000 \\
\hline
\end{tabular}




\begin{tabular}{|c|c|c|c|c|c|c|c|}
\hline Fars & 110000 & 215000 & 320000 & 425000 & 530000 & 635000 & 740000 \\
\hline Gom & 60000 & 115000 & 170000 & 225000 & 280000 & 335000 & 390000 \\
\hline Kerman & 60000 & 115000 & 170000 & 225000 & 280000 & 335000 & 390000 \\
\hline Yazd & 55000 & 105000 & 155000 & 205000 & 255000 & 305000 & 355000 \\
\hline Sum & 726000 & 1396000 & 2066000 & 2736000 & 3406000 & 4076000 & 4746000 \\
\hline
\end{tabular}

Finally, the Table 6 shows the established distribution facilities and their corresponding capacities. As shown in this Table, the number of distribution centers is higher than other facilities. The reason for this can be explained by the fact that the model prefers to establish more distribution centers to reduce the transportation costs.

Table 6. Established distribution centers and their capacities

\begin{tabular}{|c|c|c|c|c|c|c|c|}
\hline \multirow{2}{*}{ Cities } & \multicolumn{7}{|c|}{ Year } \\
\cline { 2 - 8 } & 1 & 2 & 3 & 4 & 5 & 6 & 7 \\
\hline Tabriz & 53205 & 53205 & 53205 & 53205 & 62718 & 62718 & 62718 \\
\hline Isfahan & 109554 & 126520 & 135638 & 135638 & 135638 & 135638 & 135638 \\
\hline Tehran & 121704 & 126183 & 139391 & 162631 & 170601 & 170601 & 170601 \\
\hline Khorasan R. & 91300 & 92436 & 92436 & 92436 & 92436 & 145007 & 145007 \\
\hline Khuzestan & 32946 & 32946 & 32946 & 63104 & 83693 & 83693 & 83693 \\
\hline $\begin{array}{c}\text { Sistan and } \\
\text { Baluchestan }\end{array}$ & 57974 & 64065 & 81483 & 93167 & 104852 & 104852 & 104852 \\
\hline $\begin{array}{c}\text { Fars } \\
\text { Fazvin }\end{array}$ & 90309 & 94681 & 97521 & 100447 & 123553 & 131445 & 131445 \\
\hline $\begin{array}{c}\text { Kohgiluyeh and } \\
\text { Boyer-Ahmad }\end{array}$ & 27809 & 86527 & 86527 & 86527 & 86527 & 86527 & 86527 \\
\hline $\begin{array}{c}\text { Lorestan } \\
\text { Sum }\end{array}$ & 3000 & 9118 & 9118 & 9118 & 9118 & 9118 & 9118 \\
\hline Markazi & 15205 & 15205 & 15205 & 15205 & 37511 & 37511 & 37511 \\
\hline
\end{tabular}

In this section, sensitivity analysis is performed on some important parameters of the model. First, the impact of risk coefficients on the cost objective function is investigated. Figures 5 and 6 show the importance of the coefficient $\lambda_{c}$ on the amount of possibilistic variability related to the cost objective function and the total cost objective function, respectively. As shown in these figures, when this risk factor increases, the amount of possibilistic variability decreases and the amount of the cost objective function increases. 


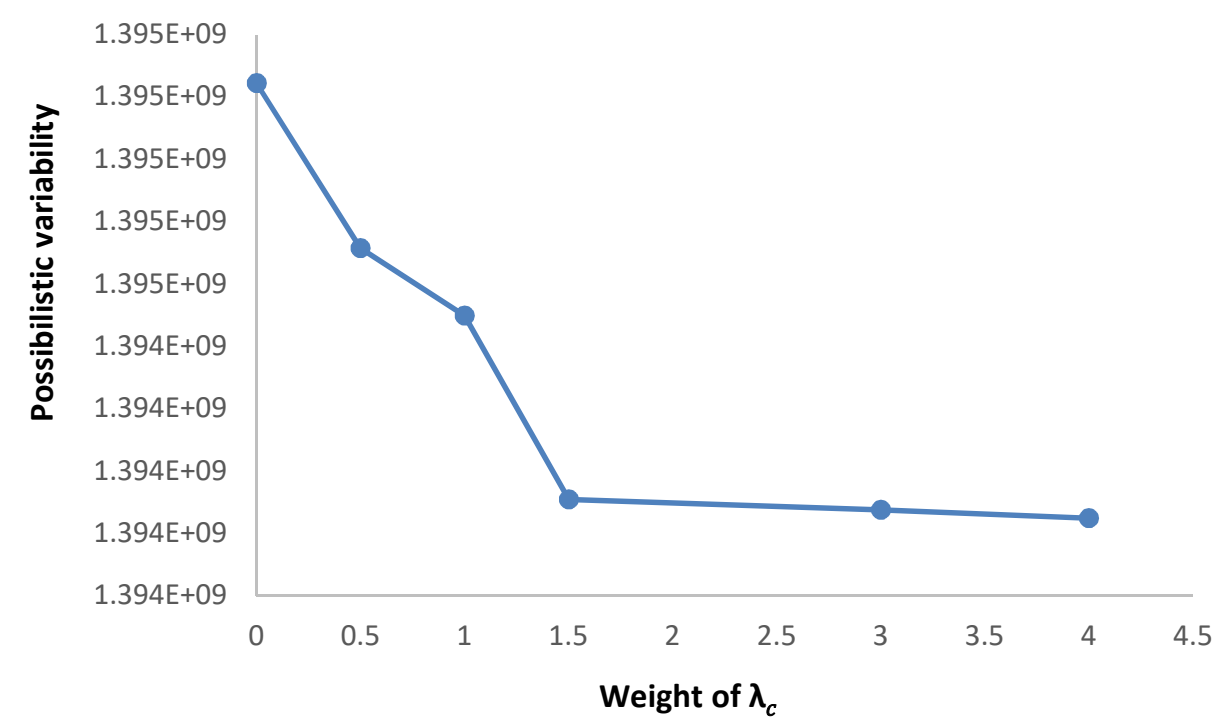

Figure 5- The impact of changes in $\lambda_{c}$ on the possibilistic variability of the cost objective function

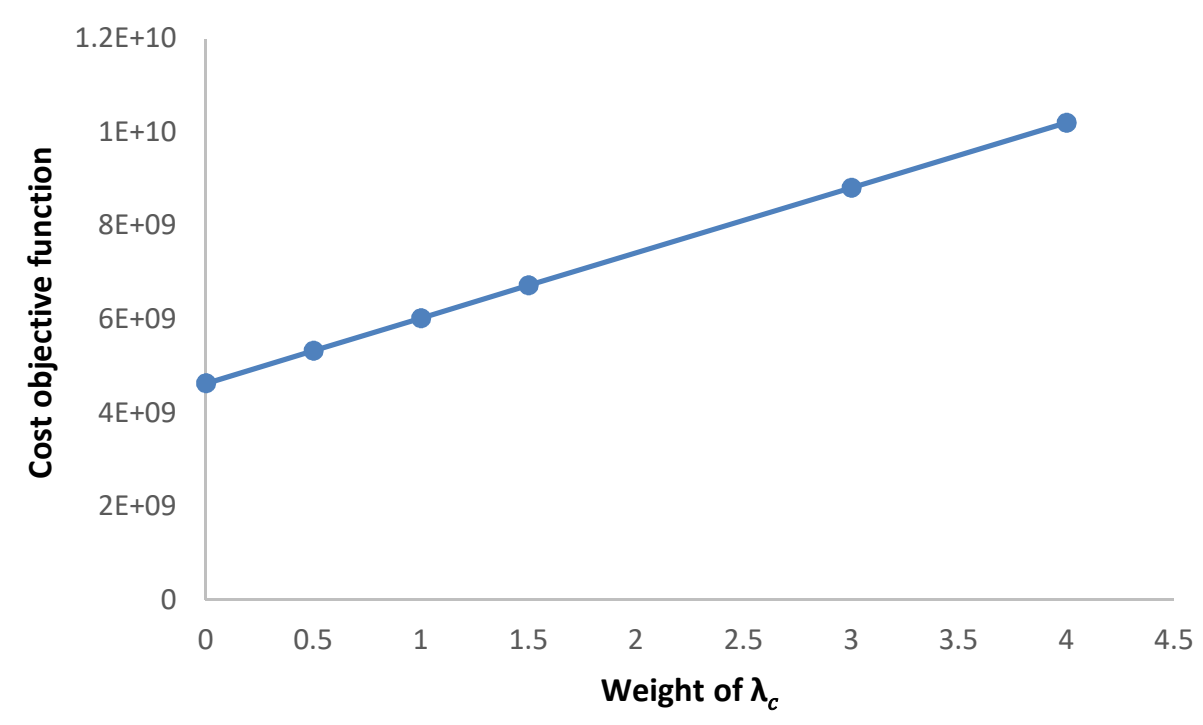

Figure 6- The impact of changes in $\lambda_{c}$ on the cost objective function

Similarly, Figure 7 and 8 show the importance of the coefficient $\gamma_{c}$ on the amount of scenario variability of the cost objective function and the total value of cost objective function. As this coefficient increases, the amount of scenario variability decreases and the value of the cost objective function increases. 


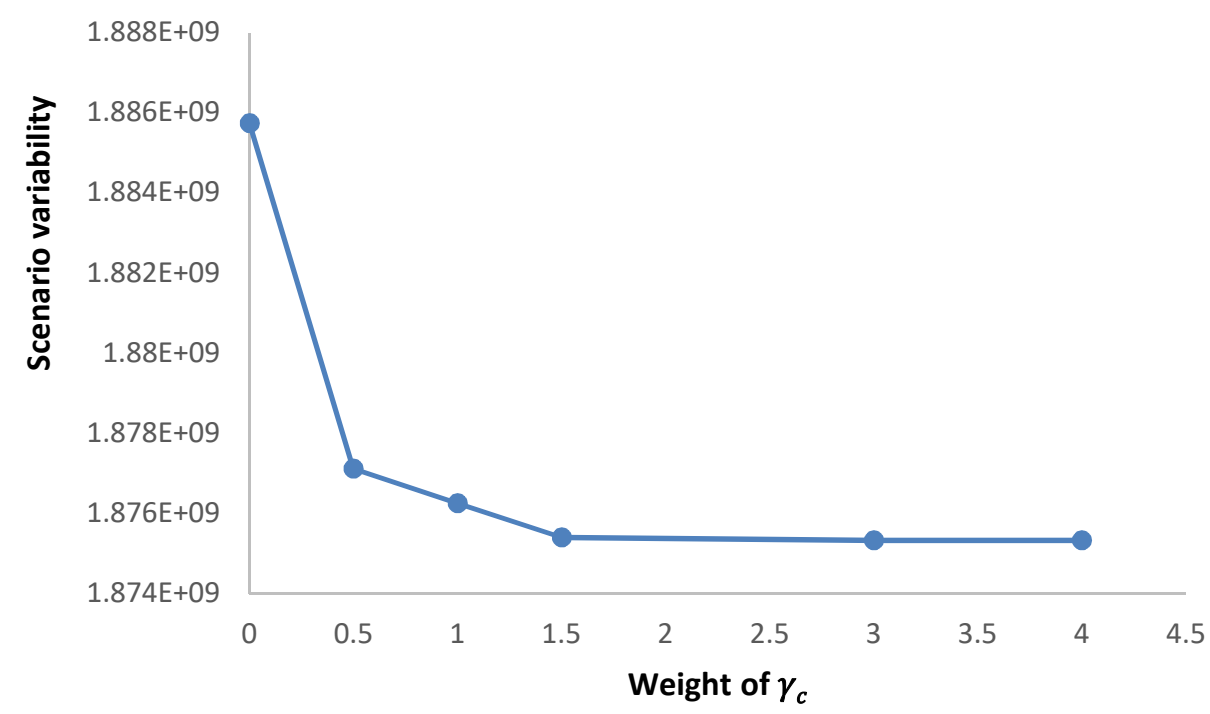

Figure 7- The impact of changes in $\gamma_{c}$ on the scenario variability of the cost objective function

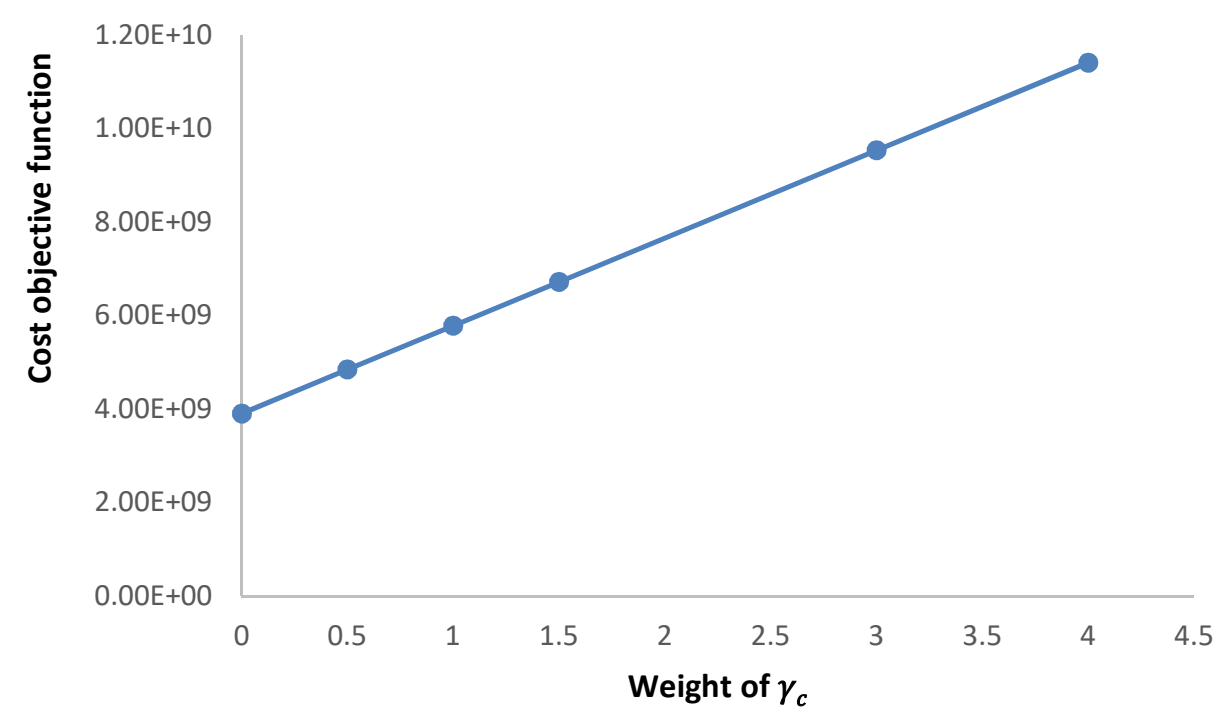

Figure 8- The impact of changes in $\gamma_{c}$ on the cost objective function

According to Figure 5 and 7, when the values of these coefficients are zero, there is the greatest risk of decision making. Because at these points, possibilistic variability and scenario variability have their maximum values. In fact, by determining these coefficients, the robustness of the optimal solutions can be controlled according to the preferences of decision makers.

Figure 9 shows the importance of the coefficient $\omega$ on the amount of unsatisfied demand cost. According to this figure, by increasing this coefficient, the amount of unsatisfied demand cost decreases. Indeed, by increasing this coefficient, the feasibility 
robustness will be high. Besides, according to Figure 10, by increasing $\omega$, the total cost will increase.

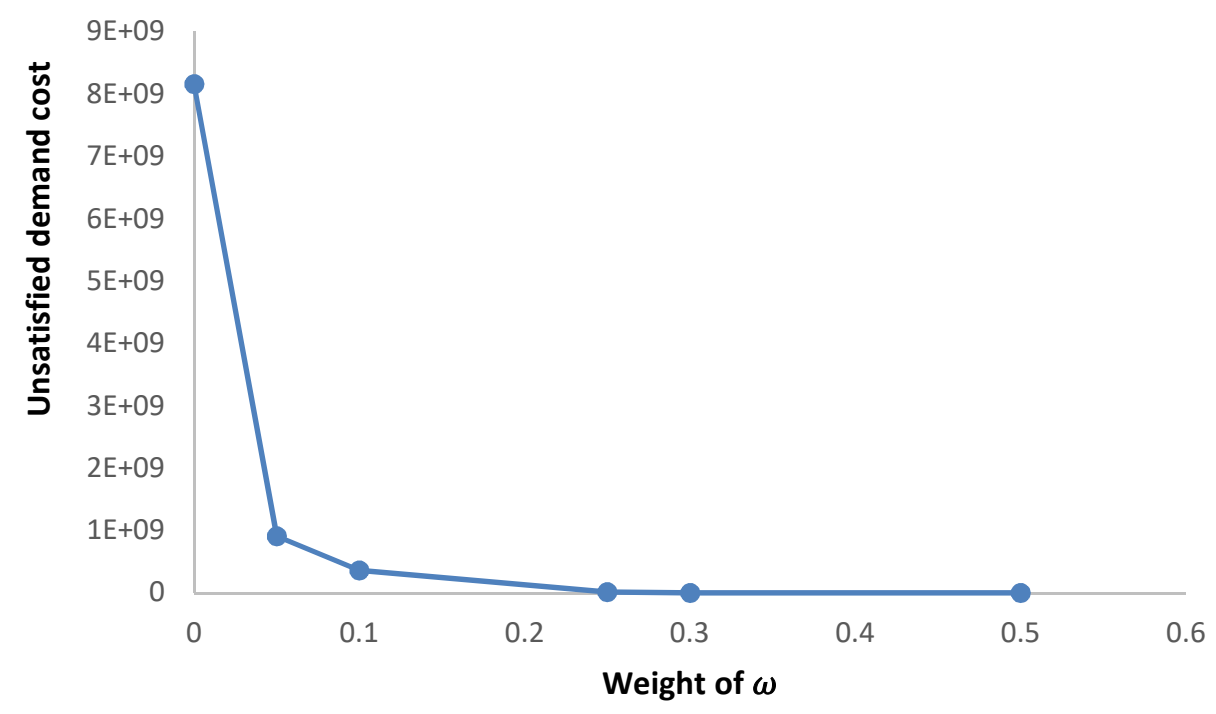

Figure 9- The impact of changes in $\omega$ on the unsatisfied demand cost

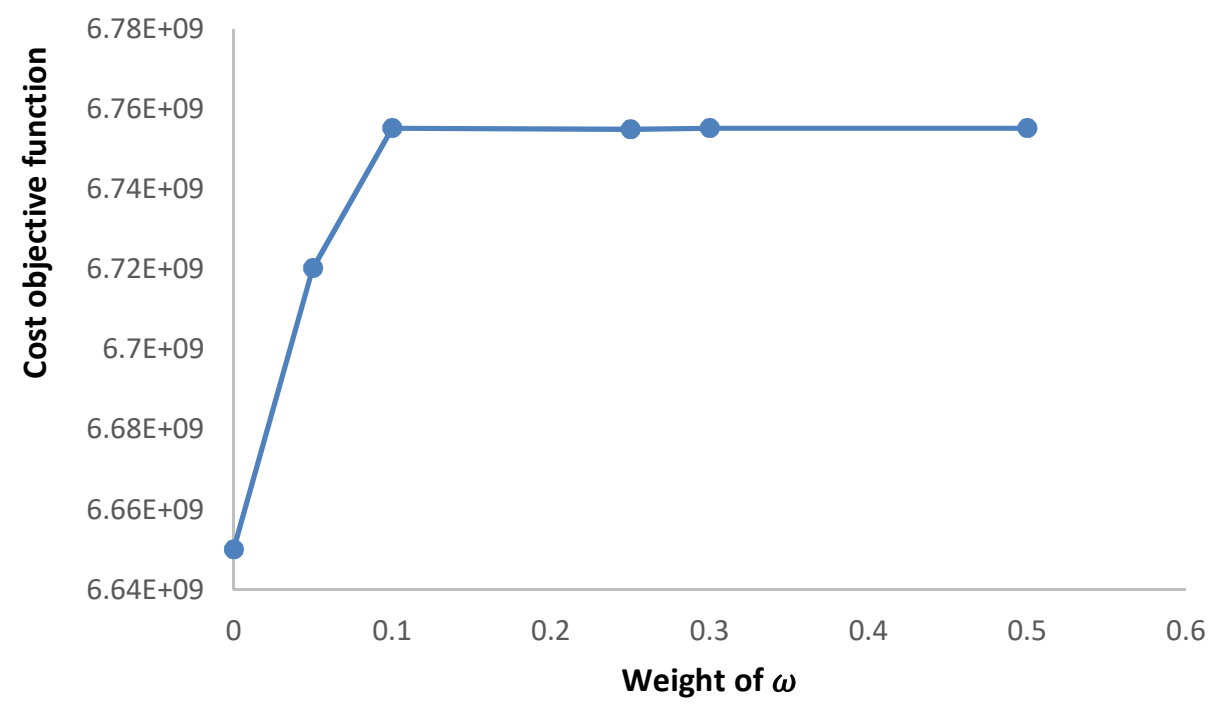

Figure 10- The impact of changes in $\omega$ on the cost objective function

In the following, the impact of risk coefficients on the environmental objective function is investigated. Figures 11 and 12 show the impact of $\lambda_{e}$ on possibilistic variability values of the environmental objective function and the values of the total environmental objective function. According to Figure 11, for different values of $\lambda_{e}$, these values remain almost constant and do not show much sensitivity to this coefficient. But as shown in Figure 12, by increasing this coefficient, the value of the environmental objective function will increase. 


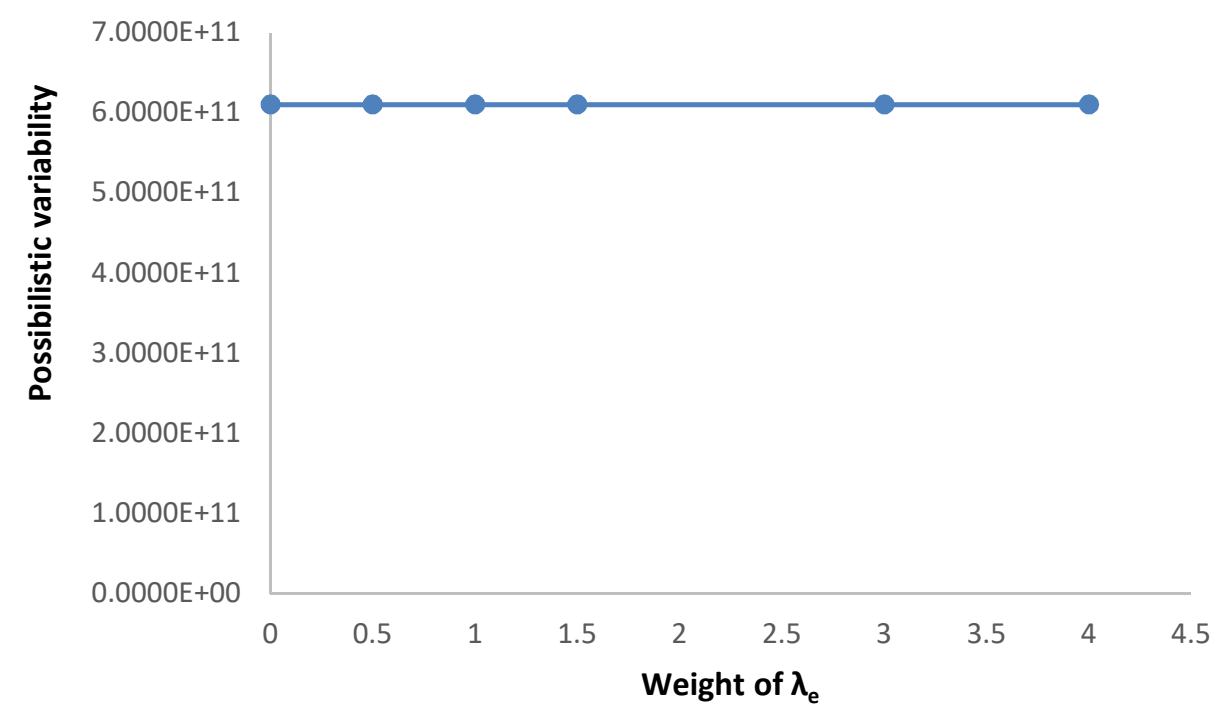

Figure 11- The impact of changes in $\lambda_{e}$ on the possibilistic variability of the environmental objective function

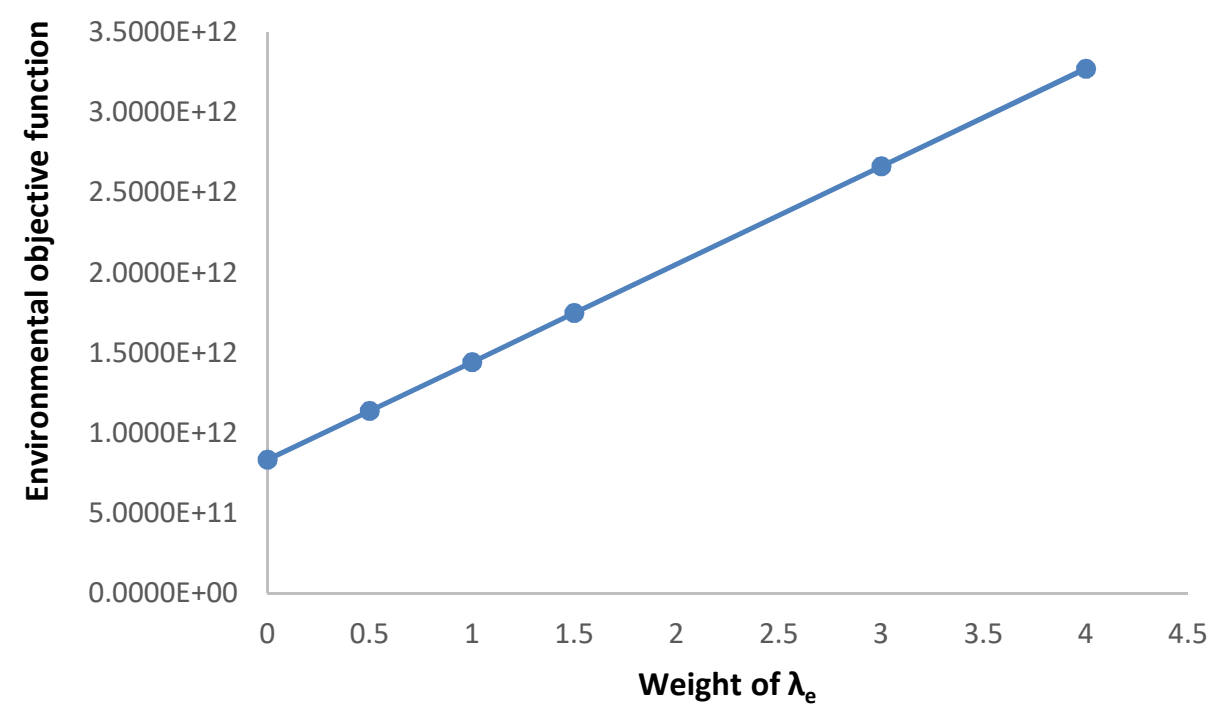

Figure 12- The impact of changes in $\lambda_{e}$ on the environmental objective function

Similarly, the scenario variability of the environmental objective function and the total value of the environmental objective function for different values of $\gamma_{e}$ are shown in Figures 13 and 14. As this coefficient increases, the amount of scenario variability first decreases and then remains constant. However, the total value of the environmental objective function increases with increasing this coefficient. 


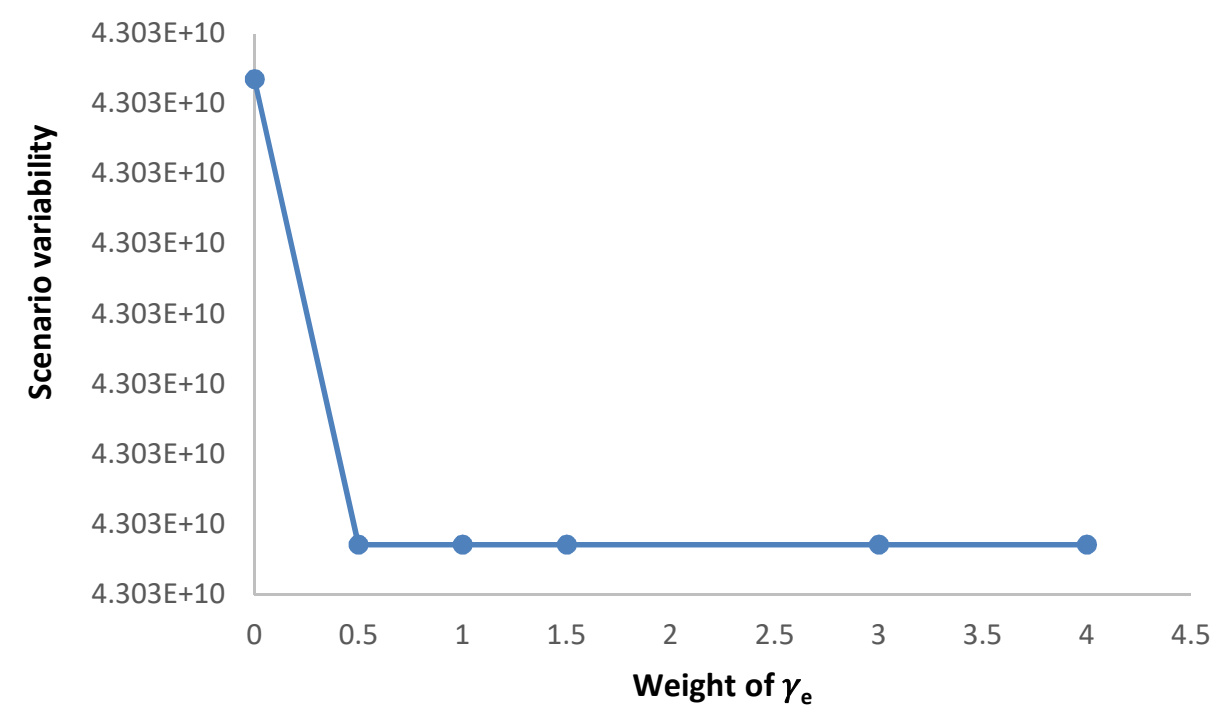

Figure 13- The impact of changes in $\gamma_{e}$ on the scenario variability of the environmental objective function

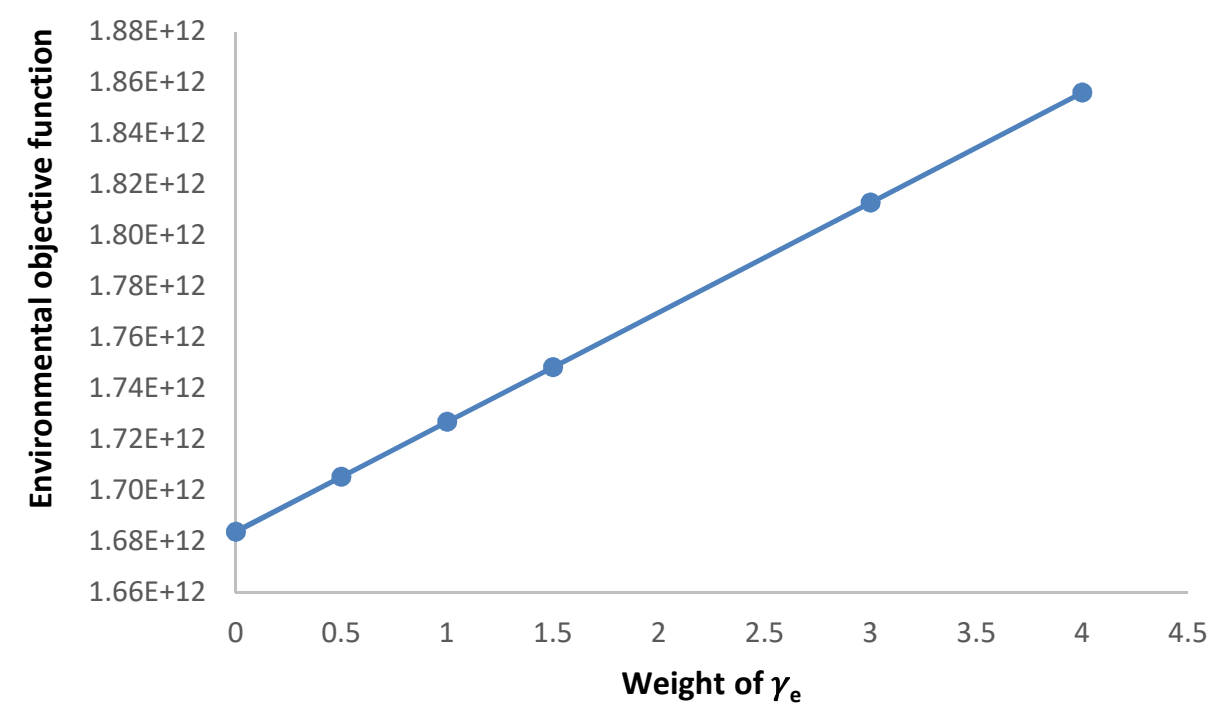

Figure 14- The impact of changes in $\gamma_{e}$ on the environmental objective function

The results of sensitivity analysis show that the sensitivity of the environmental objective function to risk coefficients is less than the cost objective function. This can be explained by the fact that the fluctuations and uncertainties of the parameters of the environmental objective function are less than the cost objective function ones.

\section{6- Conclusion}

Despite the fact that biodiesel has good properties that could be an appropriate alternative to petrodiesel, has not a large share of the energy market due to its high production cost. Effective and efficient design of BSCN can decrease a lot of of these costs. Iran has great 
potential of RE resources especially biomass. While the biomass is fairly cheap, the logistic costs are major obstacles in utilizing these sources.

Biodiesel supply chain can be subject of several uncertain parameters that may greatly affect the optimal configuration. Therefore, in this paper, a fuzzy stochastic optimization model is presented to design a BSCN under hybrid uncertainty. The amount of fixed cost for establishing the facilities, and environmental impact of opening of capacities are described as fuzzy variables. The quantity of demands, supplies and some costs (producing, inventory holding, and shipment) and some environmental impacts (producing, inventory holding, and shipment) are consider as fuzzy scenario based variables.

In this paper, a multi-objective robust fuzzy stochastic programming model is proposed for designing the BSCN under hybrid uncertainty. The presented model aims to simultaneously minimize the total cost and the total environmental impacts of activities of the supply chain network. The results show the effectiveness of the presented approach for designing the BSCN.

The proposed model is implemented in a real case study to design Iran's BSCN. Due to, importing most of edible oils and high cost of producing from these sources, utilizing edible oil sources for producing biodiesel in Iran is irrational. So, in this paper, WCO, JCL and SL are regarded as sources of producing biodiesel. The proposed model determines the optimum location, number, and capacity of the centers of JCL and SL cultivating, oil extraction, distribution and biorefineries.

\section{References}

Ahn Y-C, Lee I-B, Lee K-H, Han J-H (2015) Strategic planning design of microalgae biomass-to-biodiesel supply chain network: Multi-period deterministic model. Applied energy 154:528-542

An H, Wilhelm WE, Searcy SW (2011) A mathematical model to design a lignocellulosic biofuel supply chain system with a case study based on a region in Central Texas. Bioresource technology 102:7860-7870

Atashbar NZ, Labadie N, Prins C (2016) Modeling and optimization of biomass supply chains: A review and a critical look. IFAC-PapersOnLine 49:604-615

Awudu I, Zhang J (2012) Uncertainties and sustainability concepts in biofuel supply chain management: A review. Renewable and Sustainable Energy Reviews 16:13591368

Ba BH, Prins C, Prodhon C (2016) Models for optimization and performance evaluation of biomass supply chains: An Operations Research perspective. Renewable Energy 87:977-989

Babazadeh R, Razmi J, Pishvaee MS, Rabbani M (2017a) A sustainable second-generation biodiesel supply chain network design problem under risk. Omega 66:258-277

Babazadeh R, Razmi J, Rabbani M, Pishvaee MS (2017b) An integrated data envelopment analysis-mathematical programming approach to strategic biodiesel supply chain network design problem. Journal of Cleaner Production 147:694-707 
Babazadeh R, Razmi J, Rabbani M, Pishvaee MS (2017c) An integrated data envelopment analysis-mathematical programming approach to strategic biodiesel supply chain network design problem. Journal of Cleaner Production 147:694-707

Bai Y, Hwang T, Kang S, Ouyang Y (2011) Biofuel refinery location and supply chain planning under traffic congestion. Transportation Research Part B: Methodological 45:162-175

Bairamzadeh S, Saidi-Mehrabad M, Pishvaee MS (2018a) Modelling different types of uncertainty in biofuel supply network design and planning: A robust optimization approach. Renewable Energy 116:500-517

Bairamzadeh S, Saidi-Mehrabad M, Pishvaee MS (2018b) Modelling different types of uncertainty in biofuel supply network design and planning: A robust optimization approach. Renewable energy 116:500-517

Bertsimas D, Brown DB, Caramanis C (2011) Theory and applications of robust optimization. SIAM review 53:464-501

Cai YP, Huang GH, Yeh SC, et al (2012) A modeling approach for investigating climate change impacts on renewable energy utilization. International Journal of Energy Research 36:764-777

Cambero C, Sowlati T, Marinescu M, Röser D (2015) Strategic optimization of forest residues to bioenergy and biofuel supply chain. International Journal of Energy Research 39:439-452

Chaharsooghi SK, Rezaei M (2016) Prediction of Iran's renewable energy generation in the fifth development plan. International Journal of Services and Operations Management 25:120-133

Chaharsooghi SK, Rezaei M, Alipour M (2015) Iran's energy scenarios on a 20-year vision. International journal of environmental science and technology 12:37013718

Dal-Mas M, Giarola S, Zamboni A, Bezzo F (2011) Strategic design and investment capacity planning of the ethanol supply chain under price uncertainty. Biomass and bioenergy 35:2059-2071

Devarajan Y, kumar Jayabal R, Ragupathy D, Venu H (2017) Emissions analysis on second generation biodiesel. Frontiers of Environmental Science \& Engineering $11: 3$

Ghaderi H, Pishvaee MS, Moini A (2016) Biomass supply chain network design: an optimization-oriented review and analysis. Industrial crops and products 94:9721000

Giarola S, Zamboni A, Bezzo F (2011) Spatially explicit multi-objective optimisation for design and planning of hybrid first and second generation biorefineries. Computers \& Chemical Engineering 35:1782-1797 
Hepbasli A (2010) A review on energetic, exergetic and exergoeconomic aspects of geothermal district heating systems (GDHSs). Energy Conversion and Management 51:2041-2061

Huang R, Su R, Qi W, He Z (2011) Bioconversion of lignocellulose into bioethanol: process intensification and mechanism research. Bioenergy Research 4:225-245

Karakosta C, Askounis D (2010) Developing countries' energy needs and priorities under a sustainable development perspective: A linguistic decision support approach. Energy for Sustainable Development 14:330-338

Kim J, Realff MJ, Lee JH, et al (2011) Design of biomass processing network for biofuel production using an MILP model. Biomass and bioenergy 35:853-871

Li X, Qu F, Jiang D, Zhu P (2009) Integrated benefits of power generation by straw biomass-A case study on the Sheyang Straw Power Plants in Jiangsu Province, China. Frontiers of Environmental Science \& Engineering in China 3:348-353

Marufuzzaman M, Eksioglu SD, Huang YE (2014) Two-stage stochastic programming supply chain model for biodiesel production via wastewater treatment. Computers \& Operations Research 49:1-17

Mousavi Ahranjani P, Ghaderi SF, Azadeh A, Babazadeh R (2018) Hybrid multiobjective robust Possibilistic programming approach to a sustainable bioethanol supply chain network design. Industrial \& Engineering Chemistry Research 57:15066-15083

Pishvaee MS, Fathi M, Jolai F (2008) A fuzzy clustering-based method for scenario analysis in strategic planning: the case of an Asian pharmaceutical company. South African Journal of Business Management 39:21-31

Pishvaee MS, Khalaf MF (2016) Novel robust fuzzy mathematical programming methods. Applied Mathematical Modelling 40:407-418

Quddus MA, Hossain NUI, Mohammad M, et al (2017) Sustainable network design for multi-purpose pellet processing depots under biomass supply uncertainty. Computers \& Industrial Engineering 110:462-483

Rezaei M, Chaharsooghi SK, Abbaszadeh P (2013) The role of renewable energies in sustainable development: case study Iran. Iranica Journal of Energy and Environment 4:320-329

Rezaei M, Chaharsooghi SK, Kashan AH, Babazadeh R (2020a) A new approach based on scenario planning and prediction methods for the estimation of gasoil consumption. International Journal of Environmental Science and Technology 17:3241-3250

Rezaei M, Chaharsooghi SK, Kashan AH, Babazadeh R (2020b) Optimal design and planning of biodiesel supply chain network: a scenario-based robust optimization approach. International Journal of Energy and Environmental Engineering 11:111128

Ruiz HA, Martínez A, Vermerris W (2016) Bioenergy potential, energy crops, and biofuel production in Mexico. BioEnergy Research 9:981-984 
Salamanca H, Chang M, Tian X (2012) Costs and prices for renewable energy development in industrialized countries and applications to China. Frontiers of Environmental Science \& Engineering 6:403-411

Santibañez-Aguilar JE, Guillen-Gosálbez G, Morales-Rodriguez R, et al (2016a) Financial risk assessment and optimal planning of biofuels supply chains under uncertainty. Bioenergy Research 9:1053-1069

Santibañez-Aguilar JE, Morales-Rodriguez R, González-Campos JB, Ponce-Ortega JM (2016b) Stochastic design of biorefinery supply chains considering economic and environmental objectives. Journal of cleaner production 136:224-245

Shakouri H, Kazemi A (2017) Multi-objective cost-load optimization for demand side management of a residential area in smart grids. Sustainable cities and society $32: 171-180$

Steiner JJ, Lewis KC, Baumes HS, Brown NL (2012) A feedstock readiness level tool to complement the aviation industry fuel readiness level tool. BioEnergy Research 5:492-503

Suganthi L (2018) Multi expert and multi criteria evaluation of sectoral investments for sustainable development: An integrated fuzzy AHP, VIKOR/DEA methodology. Sustainable cities and society 43:144-156

Swain RB, Karimu A (2020) Renewable electricity and sustainable development goals in the EU. World Development 125:104693

Tan Y, Wang X, Zheng Y (2018) Modeling and daily operation optimization of a distributed energy system considering economic and energy aspects. International Journal of Energy Research 42:3477-3495

Tong K, Gleeson MJ, Rong G, You F (2014a) Optimal design of advanced drop-in hydrocarbon biofuel supply chain integrating with existing petroleum refineries under uncertainty. biomass and bioenergy 60:108-120

Tong K, You F, Rong G (2014b) Robust design and operations of hydrocarbon biofuel supply chain integrating with existing petroleum refineries considering unit cost objective. Computers \& Chemical Engineering 68:128-139

Ulonska K, König A, Klatt M, et al (2018) Optimization of multiproduct biorefinery processes under consideration of biomass supply chain management and market developments. Industrial \& Engineering Chemistry Research 57:6980-6991

Winkler H (2007) Energy policies for sustainable development in South Africa. Energy for sustainable Development 11:26-34

Xu C, Xu Q (2018) Novel design for simultaneous production of biodiesel and glycerol carbonate from soybean oil. Industrial \& Engineering Chemistry Research 57:16809-16816

Zhang Y, Jiang Y (2017) Robust optimization on sustainable biodiesel supply chain produced from waste cooking oil under price uncertainty. Waste Management 60:329-339 